\title{
Evolución histórica de las relaciones políticas y económicas de Chile con las potencias hegemónicas: Gran Bretaña y Estados Unidos*
}

\author{
Raúl Bernal-Meza
}

Chile fue desde el periodo colonial una formación social pasiva en la configuración de las relaciones internacionales. Su condición económica periférica colonial, respecto del polo del Virreinato de Lima, se proyectó hasta nuestros días a través de la dependencia bajo el orden imperial de la pax britannica y, más tarde, bajo la subordinación de la hegemonía norteamericana. Sin embargo, hubo períodos en que esa condición puđo dejar de ser una constante histórica. En el momento presente, cuando se profundizan las vinculaciones financieras y comerciales con Estados Unidos, en ausencia de disidencias políticas, es importante revisar las relaciones del país con las potencias hegemónicas, en una perspectiva histórica, comparativa y de conjunto.

\section{Introducción.}

Chile, como el resto de América del Sur, fue integrado al sistema europeo de relaciones internacionales a través de la colonización española. Sin embargo, su integración a la economía intemacional sólo se produjo -de manera formal, es decir por vía de acuerdos de comercio, tratados y otros instrumentos- luego de iniciado el proceso de independencia política, a través del comercio con Gran Bretaña.

\footnotetext{
* El presente trabajo forma parte de un proyecto más amplio sobre las relaciones intemacionales de Chile, realizado en el marco de investigaciones del Area de Relaciones Internacionales de flACSO, Argentina.
} 
Fue funcional a este proceso la adopción por las ex colonias de una política comercial librecambista y la visión de que el comercio con el mundo (y el librecambio) traía aparejado el desarrollo.

Europa, en particular Gran Bretaña y Francia, así como los Estados Unidos constituyeron paradigmas sobre los cuales los políticos chilenos reflexionaron como modelos de organización política, aunque no los aplicaron.

El carácter de las relaciones bilaterales fue desde el onigen desigual, en la medida que el acercamiento chileno hacia las potencias se relacionaba, políticamente, con la necesidad de obtener de las mismas un reconocimiento como Estado libre e independiente y, en lo económico, con la necesidad de desarrollar el comercio exterior, acceder a mercados y financiamiento; en tanto que, para las potencias, Chile fue un actor de escasa relevancia e importancia, tanto en términos políticos, como económicos y comerciales, con la excepción de la provisión de insumos considerados en ciertos períodos como "estratégicos" (salitre, cobre).

Sin embargo, visto Chile como parte de la región latinoamericana, ésta constituyó, en general, una zona de importancia y motivo de rivalidad entre las potencias, tanto europeas como con Estados Unidos. Como dice Stanley Hilton, "vista desde el ángulo europeo, la importancia de América Latina en la era de la pre-guerra tal vez se pueda medir mejor por la intensidad de la rivalidad entre las grandes potencias que por la influencia en la región. Gran Bretaña tuvo una ventaja competitiva sobre otros importantes países en la mayoría de los mercados latinoamericanos hasta 1914, entre otras cosas debido a su aventajada situación industrial y el poderío de su marina mercante".

No obstante, los intereses comerciales -cuyo reflejo eran esas rivalidades-no tuvieron su correlato en lo político. Los intereses comerciales fueron abrumadoramente más importantes que los políticos. Dice este mismo historiador norteamericano: "sólo España entre las potencias europeas demostró algún marcado interés político en la región hasta la década de 1890. La potencia extranjera más influyente en América Latina -Gran Bretaña-se limitaba a las empresas comerciales. "Los intereses estratégicos eran mínimos o inexistentes", observó en 1967 D.C. Platt. ${ }^{2}$ " Un estudio más reciente confirma este juicio de que la politica británica

\footnotetext{
' S.E. Hilton, "América Latina y Europa occidental, 1880-1945: la dimensión política", en: W. Grabendorff \& R. Roett (eds.), América Latina, Europa Occidental y Estados Unidos, (Buenos Aires: Grupo Editor Latinoamericano, 1984), p. 30.

${ }^{2}$ D.C.M. Platt, "British Diplomacy in Latin America Since the Emancipation", Inter-American Economic Affairs, 21:3, inviemo de 1967, pp. 21-39.
} 
en ese periodo fue "una combinación de indiferencia, ignorancia y negligencia, basada en la realidad de que América Latina no poseía ninguna importancia política ni estratégica para Gran Bretaña". 3 Platt y otros, además, han sostenido racionalmente que el Foreign Office ni siquiera activa ni indebidamente trató de fomentar o proteger los intereses británicos en América Latina. ${ }^{4}$

Para comprender la política británica hacia las ex colonias hispanoamericanas es necesario centrarse en el contexto global de la política exterior de esa nación y en ella ubicar la prioridad de intereses. Si bien es cierto que la primera acción político-militar y diplomática de Gran Bretaña en América del Sur se da con las invasiones al Río de la Plata, en 1806, ella se situó también en el contexto de su política europea. Como señala Klaus Gallo, "Europa, en el lapso 1806-1825, estuvo en un comienzo bajo el influjo de la dominación napoleónica, y después, tras la caída del Imperio francés, dominada por una alianza conservadora inestable entre las naciones líderes, alianza que fue considerada un medio de lograr un equilibrio pacífico de poderes. Inglaterra encabezó la lucha contra la Francia napoleónica, y después, con más timidez, resistió los designios de Metternich y la Santa Alianza. El reconocimiento de la independencia de las colonias hispanoamericanas no fue considerado seriamente en Inglaterra hasta 1824". 5

Es comprensible que, en ese contexto, las relaciones de Gran Bretaña con las ex colonias hispanas fueran una cuestión de escasa importancia en su política exterior. Como desarrollaremos más adelante, las indecisiones, la falta de convicción y la ausencia de una política definida hacia los países del Cono Sur (Chile y, en particular las Provincias Unidas del Río de la Plata), eran el resultado de las distintas estrategias que la potencia ponía en práctica ante los miembros de la Santa Alianza, en la preservación de sus intereses europeos. Asi, en la medida que las relaciones con Francia y España se complicaban, Sudamérica aparecía como una alternativa para enfrentar las políticas europeas de esas potencias; entonces, Gran Bretaña ponía mayor interés en las relaciones con Hispa-

\footnotetext{
${ }^{3}$ Joseph Smith, Illusions of Conflict: Anglo-American Diplomacy toward Latin America, 18651896, (Pittsburgh: Pittsburgh University Press, 1979), p. 21.

${ }^{4}$ D.C.M. Platt, "Business Imperialism 1840-1930: An ...", op. cit., y Charles Jones, "Business Imperialism and Argentina, 1875-1900: A Theoretical Note", Journal of Latin American Studies, 12, noviembre de 1980, pp. 437-444.

${ }^{5}$ Klaus Gallo, De la invasión al reconocimiento. Gran Bretaña y el Rio de la Plata 1806-1826, (Buenos Aires: A.Z. Editora, 1994), p. 7.
} 
noamérica, en particular el Río de la Plata. Su política fue por tanto cambiante y ambivalente.

En cambio, para los gobiernos de las recientes independizadas colonias, las relaciones con Gran Bretaña adquirían una relevancia fundamental, con el objetivo de asegurar la libertad vis-à-vis la metrópoli española.

La mayoría de los planes británicos relacionados con Sudamérica, a partir de 1780, hacia México, Perú, Chile y el Río de la Plata, tienen que ver con el objetivo de asegurar espacios para el desarrollo del comercio británico con estos nacientes mercados.

El resentimiento de Gran Bretaña hacia España y Francia, por la ayuda que nacionales de estas potencias dieron a las luchas por la independencia en los Estados Unidos, impulsó en cierto momento la discusión de iniciativas tendientes a apoyar la independencia de las colonias españolas; sin embargo, ello nunca llegó a traducirse en políticas concretas, ni siquiera en un pronto reconocimiento de la independencia, fuera en el Río de la Plata o en Chile. ${ }^{6}$ Los motivos por los cuales nunca los gobiemos ingleses habian permitido que zarpara una expedición a Hispanoamérica fueron justamente la ausencia de motivaciones políticas más allá de las puramente comerciales y que éstas fueran convincentes en términos de principios, así como en el modo de llevarlas a cabo. ${ }^{7}$

Durante el periodo inmediato a los primeros intentos independentistas, los gobiernos británicos presupusieron -erróneamente-que los sudamericanos estaban complacidos con una eventual presencia británica y -por ejemplo, en el caso argentino- con una presencia real (invasión); que no cuestionarían los términos bajo los cuales habían sido invadidos, porque preferían esta presencia al yugo español. La historia demostró lo erróneo de esta presunción.

Sin embargo, el principal problema fue que Inglaterra nunca definió cuál debía ser el carácter de su presencia en Hispanoamérica: si contribuir a la independencia de las colonias o hacer de esos territorios nuevas. colonias inglesas, aplastando así las aspiraciones de libertad de. sus pueblos.

Aunque en los hechos y en el tiempo unos gobiemos ingleses fueron más proclives que otros a analizar políticamente el tema del apoyo y

\footnotetext{
${ }^{6}$ Una exposición clara de las discusiones que se generaron en Gran Bretaña en torno a la participación británica en las luchas por la independencia $y$, posteriormente, a propósito del reconocimiento de la independencia, puede verse en Klaus Gallo, Ibid.

${ }^{7}$ Jbid.
} 
luego el reconocimiento (el caso más evidente es la diferencia entre Castlereagh y Canning), todos aspiraron a que las ex colonias hispanoamericanas adoptaran gobiemos monárquicos, por lo cual el tipo de gobierno que se dieron países como Argentina o Chile no entraban en las preferencias británicas $y$, por tanto, constituyeron un factor de recelo para Londres.

La política inglesa actuó frente a los acontecimientos en las ex colonias por reacción a lo que otras potencias europeas intentaran hacer en Sudamérica o Hispanoamérica; es decir, expandir su influencia fuera a través de la posesión de territorios o la adquisición de enclaves o condiciones favorables para el comercio. Era entonces que el tema de las ex colonias pasaba a ser considerado como un motivo de política para Londres.

Después del reconocimiento de la independencia del Río de la Plata, en 1825, luego el de Colombia y mucho más tarde el de Chile, pasarian todavía muchos años para que Sudamérica llegara a constituir un objetivo político importante para Inglaterra.

Por su parte, la política norteamericana, siguiendo la doctrina determinada por el Presidente Monroe, tuvo como horizonte impedir la interferencia europea en el continente. En este sentido, los objetivos políticos fueron: a) buscar un instrumento que debilitara las posibilidades de las potencias europeas de intervenir en los conflictos entre países latinoamericanos (como fue el caso de la Guerra del Pacífico), para lo cual impulsaron un sistema de arbitraje interamericano ${ }^{8}$ y b) impulsar una unión aduanera interamericana, también con el objetivo de debilitar a los competidores europeos. Sin embargo $-\mathrm{y}$ si bien es cierto las relaciones y recursos de poder de Estados Unidos frente a Gran Bretaña. eran escasos- no hay antecedentes "que demuestren que los Estados Unidos tuvieran al menos la voluntad politica de detener la influencia inglesa. Por el contrario, durante gran parte del siglo pasado los Estados Unidos, que ya se estaban insinuando como potencia regional, contemplaron con indiferencia la expansión inglesa, a pesar de que ella parecia contradecir el texto de la Doctrina Monroe. Con respecto a las otras potencias europeas, cuyas incursiones en América Latina fueron más políticas que económicas, la actitud norteamericana también fue de indiferencia, por lo menos durante toda la primera mitad del siglo

\footnotetext{
${ }^{8}$ Russell H. Bastert, "A New Approach to the Origins of Blaine's Pan American Policy", Hispanic American Historical Review, 39, August 1959, pp. 377-78, 383-84, 411-12.
} 
pasado". " La rivalidad entre las potencias europeas y Estados Unidos, por la posición e influencia en América Latina se interisificó a partir de la Primera Guerra Mundial y durante el periodo de entre guerras. Sin embargo, la posición hegemónica de los Estados Unidos fue un proceso irreversible justamente a partir de 1915 .

Por su parte, la política exterior chilena se enfrentó desde el nacimíento de la nación con el problema del rechazo al reconocimiento como Estado independiente. Las grandes potencias, entre 1830 y 1836 , y hasta la guerra contra la Confederación Perú-Boliviana (1839), rechazaron aceptar a Chile como un igual. La política de Chile hacia ellas fue a partir de allí una acción de mantenimiento destinada a alcanzar metas internas que le hicieran ganar el respeto y el reconocimiento de los más importantes Estados del mundo, evitando controversias y esforzándose por desarrollar con ellas lazos económicos y comerciales. ${ }^{10}$ Aún después de esa guerra, los líderes chilenos reconocían sư incapacidad para influenciar la política de las grandes potencias. ${ }^{11}$ No obstante, el pensamiento de Portales -de rechazo y oposición a los imperialismos-como connotación de un evidente nacionalismo, contribuirá a formar una tradición en la política exterior chilena más proclive al aislamiento que a la vinculación estrecha con las potencias, en particular con Estados Unidos.

\section{Las relaciones con Gran Bretaña.}

Las primeras relaciones de nacionales chilenos con Gran Bretaña vienen de la Colonia: una mezcla de relaciones comerciales (contrabando) e influencias intelectuales y políticas, las que sin embargo no trascienden a reducidos círculos de la sociedad santiaguina.

Los primeros planes ingleses acerca de una eventual incursión en las costas chilenas son de 1780. La importancia del mercado sudamericano para el comercio británico aparece en la agenda politica del gobiemo inglés ya perfilada en 1800; debates que se centraron alrededor de los ministros de Guerra y de lnterior.

\footnotetext{
9 Alberto van Klaveren, "Los antecedentes históricos del Sistema Interamericano", en: Rodrigo Diaz Albónico (ed.), Antecedentes, balance y perspectivas del Sistema Interamericano, (Santiago: Editorial Universitaria, Instituto de Estudios Internacionales de la Universidad de Chile, 1977), p. 41.

${ }^{10}$ Robert N. Burr, By Reason or Force: Chile and the Balancing of Power in South America (I830-1905), (Berkeley/Los Angeles: University of California Press, 1967), pp. 21-22.

${ }^{1 i}$ ibid., p. 59.
} 
La presencia política formal seguirá mucho más tarde a la presencia económica. La primera relación estrecha -que implica en cierta forma un reconocimiento a la soberanía de la naciente república de Chile- es el préstamo de un millón de libras esterlinas, hecho por los británicos, en 1822 , que es "orgullosamente citado como el primero a una República naciente". 12

Según este mismo autor, aunque la ayuda británica, tanto política como económica, fue importante para Chile en los años:de 1820 , la influencia británica se haría más pronunciada después de 1831, año en que Gran Bretaña reconoce a Chilẹ. Para 1836, el comercio anual de Gran Bretaña con la pequeña república superaba por mucho al total del comercio de Estados Unidos con toda la costa de Sudamérica. ${ }^{13}$

La posición de Gran Bretaña respecto de Chile y las restantes naciones hispanoamericanas, no fue uniforme durante este periodo. Bajo Lord Castlereagh, la potencia fue proclive a una intervención de "pacificación", tal como lo pedía España, aunque en general se mirara con simpatía a la revolución americana.

Castlereagh aparece inicialmente como adhiriendo a una empresa que ayudara a la emancipación de las colonias españolas, con el fin de obtener réditos comerciales e impedir eventuales planes de expansión franceses; sin embargo está lejos de apoyar la independencia. En carta que envía a Lord Strangford, representante británico en Río de Janeiro, con fecha 13 de julio de 1812, señala su interés en que los habitantes de Hispanoamérica se mantengan leales a "su legítimo soberano, Fernando VII".14 Castlereagh compartía muchos de los intereses de la Santa Alianza, en especial aquellos relacionados con detener las ideas liberales, con el fin de fortalecer las monarquías borbónicas. De ello resulta evidente, que el estadista privilegiaba las relaciones de Inglaterra con sus aliados europeos de la Santa Alianza, por sobre los beneficios eventuales que pudiera traer un temprano apoyo a las ex colonias.

Posteriormente la potencia será contraria a los propósitos intervencionistas de la Santa Aliariza, en una región que abría grandes perspectivas a su comercio. Inglaterra manifiesta en dos ocasiones, en 1820 y 1822 , su posición contraria a la orientación que se pretendía dar a la Santa Alianza, señalando que "ella no ha sido destinada jamás a convertirse en

\footnotetext{
${ }^{12}$ Lawrence Littwin, An integrated view of Chilean foreign policy, (An Asbor, Michigan: New York University/University Microfilms Inc., 1967), pp. 50-51.

${ }^{13} \mathrm{Ibld}$.

${ }^{14}$ Klaus Gallo, op. cit., p. 149.
} 
una unión para el gobiemo del mundo o a la inspección de los asuntos internos de los otros Estados". 15 Sin embargo, será con la llegada de George Canning que fue posible obtener de la potencia una posición políticamente más favorable al proceso emancipador.

Canning orientó la política británica hacia América hispana en función de los intereses políticos y económicos de su nación y adhirió a la posición del Presidente Monroe, en el sentido que Europa no podría ocupar territorios americanos ni intervenir en los asuntos internos de los países del continente.

Canning contribuyó a impedir que España recuperara sus colonias, evitando al mismo tiempo que otras potencias europeas se alzaran con ellas. Como dice Juan Carlos Puig, el hecho de que las ex colonias no pasaran a integrar el potencial de las potencias europeas facilitó el equilibrio de poder en la región; ${ }^{16}$ pero, al mismo tiempo, ello facilitaba a Gran Bretaña su posición de poder en Europa, así como la continuidad de un equilibrio de poder europeo que le fuera funcional. "Cuando los países latinoamericanos recientemente independizados entraron en la esfera de influencia británica, desde los puntos de vista comercial y financiero, se incrementó la potencia marítima y económica británica, 10 que a su vez facilitó el rol británico como "guardián del equilibrio europeo" 17

Es paradójico que Canning, a pesar de ser también proclive a que Sudamérica se volcara hacia gobiemos monárquicos, no puso esta cuestión como factor central de la relación, sino que buscara la forma en que la política inglesa hacia las ex colonias le ayudara en su estrategia defensiva contra las ambiciones conservadoras de la Santa Alianza, por lo cual estuvo entonces dispuesto a aceptar que los nacientes Estados se dieran formas republicanas de gobierno.

Luego de la etapa de reconocimiento -con la firma de tratados de amistad, comercio y navegación-las relaciones entraron en una etapa de escasa importancia, dado el interés que Inglaterra mostraba en expandir sus intereses en el nuevo continente. Sin embargo, su influencia, comercial, financiera, industrial y militar -que llevaba implícita una fuerte dosis de poder-no se tradujo en políticas concretas de subordinación.

\footnotetext{
${ }^{15}$ Citado por Luis Barros Borgoño, "Las primeras relaciones diplomáticas de las naciones americanas", Revista Chilena de Historia y Geografia, Sociedad Chilena de Historia y Geografia, Santiago, Imprenta Universitaria, Tomo LXXXIII, 1937, p. 60.

${ }^{16}$ Juan Carlos Puig, "Los Estados Unidos y Europa Occidental: su lugar en la politica intemacional latinoamericana", en: W. Grabendorff \& R. Roett (comps.), op. cit., p. 332.

${ }^{17}$ Ibid.
} 
Gran Bretaña no buscó ejercer el poder político en forma directa en los países de América Latina; pero tampoco permitió que otras potencias europeas lo hicieran. "Le bastaba mantener una alta cuota de influencia en cada país latinoamericano con el fin de inducir a las autoridades locales a que tomaran las decisiones más adecuadas a sus intereses económicos y políticos. Pero esta estrategia general no fue obstáculo para que en ciertas ocasiones los ingleses intervinieran fisicamente en América Latina en defensa de sus intereses". 18 Graham-Yooll ha recopilado algunas de estas intervenciones británicas en América Latina, haciendo un detalle cronológico de las mismas, aunque sin diferenciar abiertamente las características directas o indirectas de ellas. 19

Chile ingresa tarde a los intereses políticos británicos en América hispana. Londres reconocerá a Chile seis años después que a las Provincias Unidas del Río de la Plata, y también después de reconocer a México y Colombia.

Las legaciones diplomáticas de carácter permanente entre Londres y Santiago se establecieron en 1831. El primer tratado firmado entre ambos está fechado el 19 de enero de 1839; pero sólo en 1854 se suscribió entre ambos gobiernos un verdadero Tratado de Amistad y de Comercio.

Inglaterra comienza a reaiizar inversiones directas en Chile en el sector minero vinculado con el salitre, aunque es aún dificil hablar de inversión "nacional" con ese carácter, ya que se trata de inversiones de un súbdito británico radicado en Chile. No obstante, la mayoria de los empréstitos externos de Chile siguieron siendo levantados en Londres, proceso que seguirá así hasta el fin de la Primera Guerra Mundial.

Sin embargo, a pesar que Chile era un país de reducidas dimensiones, su mercado fue muy importante para Gran Bretaña, lo que explica por ejemplo que la Cámara de Comercio de Manchester fuera uno de los sectores que más presionara al gobierno inglés para que éste nombrara cónsules en las poblaciones más importantes de Chile. ${ }^{20}$

La posición predominante del comercio británico en el comercio exterior chileno para gran parte del siglo XIX ya habia quedacio establecida para la década de 1830. La caracteristica más importante del comercio de importación chileno era ya entonces la preponderancia de

\footnotetext{
${ }^{18}$ A Jberto van Klaveren, op. cit.s p. 40.

${ }^{19}$ Andrew Graham-Yooll, Pequeñas guerras británicas en América Latina, (Buenos Aires: De.Legasa).

${ }^{20}$ Arthur Rediford, "Manchester merchants and foreign trade 1794-1858", Economic history series, No11, Publications of the University of Manchester, Manchester, 1934, p. 100.
} 
mercaderas nglesas. ${ }^{21}$ Aunque el comercio de Inglaterra con Chile era menos importante que con el Brasil o la Argentina, era muy considerable. No obstante, una parte importante de las importaciones británicas eran luego reexportadas a otros países de la costa oeste de América del Sur: La posición del pueito de Valparaíso era, en este sentido, estratégica para la expansión del comercio inglés.

En 1821 se calculaba que el comercio inglés con Chile alcanzaba el millón de libras esterlinas al año, mientras que el total de las exportaciones inglesas e irlandesas a todos los países de Centro y Sudamérica era de 4.218.893 libras esterlinas. ${ }^{22}$ Heman Allen, un agente comercial norteamericano en Chile señalaba en 1825 que los mercados chilenos "estaban inundados con mercadería inglesa, y que los metales preciosos del pais... se consagraban casi exclusivamente a ese comercio". 23 .

El mercado chileno y su capacidad de reexportación fueron particularmente importantes para la industria algodonera de Lancashire. Las importaciones chilenas de algodón, para 1831, excedieron las cantidades que Gran Bretaña exportó a Rusia, a Escandinavia, a Turquía y a Grecia, al Perú, a México, a Java, Sumatra y otras islas del mar de la India. "Igualaron aproximadamente una tercera parte de la tela de algodón que importaron los territorios de la East India Company, Ceylán y China, y fueron dê igual proporción a tales importaciones por los Estados Unidos".24 Sin embargo, el sector textil no era el único de importancia: en 1828 , Gran Biretaña exportaba a Chile el $1 \%$ de sus exportaciones de acero, hierro forjado y no elaborado y más del $1 \%$ de su talabartería, además de cacharrería, ferretería y cuchillos.

La expansión del comercio británico en Chile se había iniciado en 1818. Para entonces ya varias casas inglesas operaban en Valparaíso. Los banqueros Frederick Huth and Co. establecieron la casa Huth y Compañía en Valparaíso en el año 1824, mientras que la importante casa Gibbs abrió dos años después una sucursal en ese mismo puerto. ${ }^{25}$ Estas compañías no sólo se ocuparon del comercio (importación y exportación), sino también actuaron como fuentes de crédito para la explotación minera y el desarrollo de industrias chilenas.

${ }^{21}$ Charles W. Centner, "Relaciones comerciales de Gran Bretaña con Chile. 1810-1830", Revista Chilena de Historia y Geografia, No103, Santiago, Imprenta Universitaria, 1943, p. 96.

22 Ibid., p. 97.

${ }^{23}$ Heman Allen a John Quincy Adams, 4 de mayo de 1825, $\mathrm{N}^{\circ} 14$, United States Department of State Archives, "Diplomatic dispatches received: Chile", Vol. 1, Valparaiso.

${ }^{24}$ Ibid., p. 99.

${ }^{25}$ Anibal Escobar \& Joaquín Blaya A. (eds.), El progreso británico en Chile. Historia: comercio, indusiria, (Santiago: 1919), p. 125. 
Por parte de Chile, su participación en las importaciones británicas fue muy marginal, en relación a otros países como Argentina, Brasil y Uruguay, fundamentalmente porque carecía de productos derivados del ganado. Señala el historiador norteamericano Charles W. Centner que las exportaciones de Chile a Gran Bretaña, en ese periodo, rara vez excedieron el $4 \%$ de sus importaciones de aquella nación. Los principales productos exportados por Chile eran cobre, quinina y pieles de nutria. ${ }^{26}$, La base de la expansión comercial británica en Chile fue la presencia de su marina mercante y su sólida posición continuó hasta el año 1870. Entre 1844 y 1898, las importaciones chilenas desde Gran Bretaña excedieron en valor a las de Alemania, Francia y los Estados Unidos juntos, ${ }_{2}^{27}$ lo que pone de manifiesto la hegemonía económica de Gran Bretaña en Chile.

Sin embargo, poco fue lo que el comercio contribuyó, hasta después de 1850 , en el estrechamiento de relaciones políticas y ese comercio tampoco se benefició de acciones directas o de un empeño constante del gobierno inglés.

Durante la Guerra del Pacífico Inglaterra tuvo una participación indirecta que, según los enemigos de Chile de entonces, fue claramente de apoyo a Santiago. Lo cierto es que luego del conflicto, tanto las relaciones económico-financieras (fuertes inversiones en la industria del salitre) y las político-militares aumentan considerablemente.

Durante la Guerra del Pacífico, Inglaterra, junto a Alemania y Francia, buscaron la intervención de las potencias en el conflicto, en favor del Perú. Trataban de propiciar un armisticio que volviera las cosas al statu quo anterior. Esta política fue rechazada por Estados Unidos, no porque Washington apoyara a Chile, sino porque ello afectaba su pretendida posición de hegemonía en una zona que ya consideraban de su esfera de influencia.

Esta intervención inglesa en favor del Perú fue, al parecer, un intento de recuperar sus inversiones en la industria salitrera en territorios peruanos que, con el desenlace del conflicto, estaban ahora en manos chilenas. Lo que es una realidad es que tanto Inglaterra como Estaḑos Unidos aprovecharon el conflicto entre Chile y Peni-Bolivia para mejorar sus respectivas posiciones de poder (político y económico) en los países del Pacífico Sur.

\footnotetext{
${ }^{26}$ Charles W. Centner, op. cit., p. 98.

${ }^{27}$ Oficina Central de Estadisticas de Chile, Sinopsis estadistica de la República de Chile en 1898 , (Santiago: 1899), p. 167.
} 
Los intereses económicos de súbditos ingleses en Chile crecen enormemente luego de finalizada la Guerra del Pacífico. En efecto, los capitales ingleses, que en 1875 sólo tenían el 15\% de las estacas salitreras en explotación, pasaron a controlar el $34 \%$ en 1882 y, para 1890 , el $70 \%$ de las oficinas salitreras eran de propiedad de ingleses. Capitales de ese país controlaban entonces también los ferrocarriles, los bancos y las empresas de agua potable, gas y alumbrado de la zona minera del norte chileno.

La influencia y el peso de estos intereses debían ser la fuente de la más importante intervención inglesa en la política interna chilena, apoyando la revolución contra el Presidente Balmaceda, cuyo programa económico amenazaba la posición hegemónica de éstos en la economía nacional.

El desarrollo y la expansión de la actividad salitrera, tanto en el Perú como luego en Chile, estuvo ligada a la participación de hombres y capitales británicos en alianza con poderes locales. El primer inglés que participó en la industria salitrera fue George Smith, que inició sus actividades en el sur del Perú en 1827. "Poco después de 1850, Smith, en compañía de varios otros ingleses que habian llegado poco antes a Atacama, organizó una compañía de bórax. Construyó también un andarivel, línea de cable que llevó a la construcción de la vía férrea en Tarapacá, y fue el primero que instaló condensadores de agua potable para las ciudades costeras del desierto. En 1865, junto con Melbourne Clark y William Gibbs y Cía. formó The Tarapacá Nitrate Company. Durante los siguientes diez años fue un constante gotear de ingleses en los campos del salitre. El número que llegó no fue sin embargo tan grande como a veces se supone, y en la época de la expropiación, las oficinas establecidas por el capital británico producían sólo alrededor del $12 \%$ de la producción anual de cerca de 18 millones de quintales".28 Un segundo inglès de gran importancia fue John Dawson, que en 1877 pasó a ser gerente del Banco de Londres en Valparaíso. Diez años antes este banco había prestado millones de pesos a la industria salitrera. El tercer inglés fue el coronel John Thomas North, que formaria con los anteriores el Ilamado triunvirato del salitre. North, luego de desempeñarse como ingeniero en algunas oficinas salitreras de Tarapacá y hacer importantes negocios en el sector de servicios (agua potable, representación de agencias de navegación, etc.), se inició en la compra y venta de propie-

${ }^{28}$ Osgood Hardy, "Los intereses salitreros ingleses y la Revolución de 1891", Revista Chilena de Historia y Geografia, Santiago, Sociedad Chilena de Historia y Geografia, Imprenta Universitaria, No113, 1949, p. 67. 
dades salitreras. "Cuando estalló la Guerra del Pacífico, North, ahora coronel, se encontraba en Europa, y regresó a Iquique en 1880. Su primer rasgo fue conquistar el favor de los conquistadores chilenos, vendiéndoles uno de sus vapores a un precio moderado, prestándoles un segundo para el transporte de los soldados heridos y ofreciendo a la armada chilena ocho chalupas que se necesitaban para las operaciones de desembarco. Como resultado, cuando el Vice-Almirante Lynch dispuso de un enorme depósito de guano capturado, se dieron al coronel North los derechos de venta por 40.000 toneladas. De la venta de ese guano, North se las arregló para obtener una ganancia de 4.000.000 de francos", 29 que invertiría en la compra de estacas salitreras. A partir de allí, North haria una alianza con Harvey y Dawson, que lograron hacer una inmensa fortuna comprando los certificados de expropiación del salitre, emitidos por el gobiemo peruano, a un valor de 25 libras, cuando su valor era de 183 libras esterlinas. Dawson, del Banco de Valparaíso, concedió a sus compatriotas las letras de crédito necesarias para acumular el capital suficiente como para comprar dichos certificados que, más tarde, serian reconocidos por el gobierno chileno. "Harvey seleccionó las áreas que deberían ser explotadas, Dawson proveyó de los fondos necesarios y North formó las compañías que compraron las propiedades salitreras que el trio había adquirido. En pago adquirieron acciones con lo cual multiplicaron sus ganancias". 30 Las inmensas ganancias que lograron con la explotación del salitre, fueron aumentadas con las producidas por el ferrocarril y las del gas. Gran Bretaña monopolizaba la comercialización y el transporte del salitre, ${ }^{31}$ que entonces constituia la parte fundamental de los ingresos fiscales de la nación.

Este considerable poder económico se tradujo en influencia e intervención política. "En su feudo del salitre también comenzaron tumultos contra la situación, en la cual ningún intendente podía gobernar sin la aprobación del potentado inglés. Lo más peligroso de todo fue el hecho de que don José Manuel Balmaceda estuviera convertido en Presidente de Chile. En 1886, inmediatamente después de su elección, el jefe del poder ejecutivo había dictaminado que Tarapacá debía tener adecuados ferrocarriles, mientras que el 29 de enero de 1886 el Ministro de Justicia

\footnotetext{
${ }^{29}$ Ibid., p. 70.

${ }^{30}$ Ibid., p. 71.

${ }^{31}$ Luis Vitale, Interpretación marxista de la Historia de Chile: ascenso y declinación de la Burguesia Chilena (1861-1891), de Pérez a Balmaceda, (Sartiago: Liberrarte/lomediciones/CELA, T. IV, 2a. edición, 1993), pp. $255-256$.
} 
de Chile anunciaba la cancelación de las concesiones sobre las cuales descansaba el ferrocarril de North en Tarapacá". ${ }^{32}$

North trató de obtener del Presidente Balmaceda garantías para sus inversiones, lo que implicaba en los hechos el renunciamiento de la política gubernamental propuesta para el norte salitrero.

Balmaceda trató de neutralizar la importancia de los capitales.ingleses atrayendo inversiones norteamericanas; sin embargo, sus planes fueron trabados por el conflicto con el Congreso y los grupos económicos que se veían perjudicados con su política, todo lo cual llevaria a la Guerra Civil de 1981. Según algunos historiadores, los revolucionarios que se oponían a Balmaceda recibieron, en los primeros cien días de lucha, quince millones de pesos de parte de los salitreros y luego obtuvieron un crédito de 25 millones del Banco de Tarapacá. Al término de la Guerra Civil, entre 3 y 4 millones de pesos, de los 17 millones gastados por los vencedores, habian sido provistos por los reyes del salitre. ${ }^{33}$ En 1895 , poco antes de la muerte del "rey del salitre", el coronel North, aproximadamente el $60 \%$ de la industria salitrera se encontraba en manos del capital británico, a pesar de las nacionalizaciones realizadas conforme a una ley del 29 de noviembre de 1893. ${ }^{34}$

La participación británica en la Guerra Civil es aún un tema de debate en la historiografía chilena. ${ }^{35}$ Osgood Hardy, en contra de la opinión de otros historiadores norteamericanos, señala que "parece:digno de destacar aquí la evidencia que indica que los intereses de los salitreros británicos juegan un papel significativo al inspirar a los Congresistas la rebelión contra los Balmacedistas" ${ }^{36}$ Según Davis, Finan \& Peck, la rebelión contra Balmaceda -de acuerdo a los rumores- habia sido respaldada por intereses británicos ligados al salitre, que buscaban así evitar la nacionalización que impulsaba el Presidente José Manuel Balmaceda ${ }^{37}$ Vitale coincide en que la política de Balmaceda afectaba los

\footnotetext{
${ }^{32} \mathrm{Hardy}$, op. cit., p. 73.

${ }^{33}$ Roberto Hemández Comejo, El Salitre, (Valparaiso: 1905), p. 140; Osgood Hardy, op. cit., pp. $79-81$.

${ }^{34}$ Ibid., pp. 80-81.

${ }^{35}$ Los historiadores chilenos conservadores, que se caracterizan por su defensa de los argumentos de aquellos que se levantaron en contra del gobiemo constitucional, niegan cualquier vinculación de los antibalmacedistas con el capital inglés; más aún, señalan como única fuente de conflicto la que surgió de la oposición entre el Presidente y el Congreso. Por su parte, aquellos historiadores que rescatan la figura de Balmaceda no dudan en señalar la vinculación estrecha que hubo entre sus opositores y el gran capital británico en Chile.

${ }^{36}$ O. Hardy, op. cit., p. 61.

${ }^{37}$ Harold Eugene Davis, John J. Finan \& Taylor F. Peck, Latin American Diplomatic History (an introduction), (Baton Rouge/London: Louisiana State University Press, 1977), p. 138.
} 
intereses británicos en el pais. ${ }^{38}$ Señala Osgood Hardy que "Alberto Fagalde, un conocido periodista contemporáneo, informó que todos los habitantes extranjeros de Valparaiso deseaban la caida de Balmaceda, y agrega este autor en nota a pie de página que "Fagalde también cita un editorial (La Guerra de Chile) en El Globo de Madrid, 28 de agosto de 1891 , en que se afirma que los partidarios del Congreso...cuentan con el apoyo de los capitalistas, de las clases mercantiles y de los propietarios de las minas de nitrato que constituyen la principal riqueza de la República". ${ }^{39}$ Este mismo historiador señala que "un cuadro aún más franco del significado de la influencia británica en la Guerra Civil proviene justamente de fuentes británicas. Los ingleses sentianse especialmente orgullosos del papel jugado por sus compatriotas en el desarrollo industrial de Chile, y en algunas oportunidades no vacilaron en proclamar abiertamente que el desarrollo material de Chile constituye principalmente la creación de la empresa inglesa. Y puesto que Balmaceda cercenaba las actividades salitreras de John Bull, jamás se puso "pedal suave" a la antipatía británica hacia el Presidente, teniendo como resultado que muy comúnmente los revolucionarios se jactaran de que tentan el respaldo de los intereses de todo el salitre como también el apoyo moral del gobierno y de la armada británicos". 40

Hasta 1915, año en que Estados Unidos pasa a ser el principal socio externo chileno, el comercio chileno-británico es de lejos el más importante.

Hacia la última década del siglo XIX y comienzos del XX, si bien Gran Bretaña sigue siendo el actor externo más importante para Chile, otras dos potencias europeas comienzan a ocupar también sus preferencias: Franciay Alemania. Sin embargo, fue con Gran Bretaña donde el abaniço de las relaciones era más amplio: préstamos, comercio y una gran influencia sobre la marina de guerra chilena.

Por ello es que la Primera Guerra Mundial va a crear a Chile un "problema de lealtades", que, según nuestra perspectiva, Santiago resolvió por via de una neutralidad sui generis, no exenta de ambigüedades.

Durante ese conflicto, Gran Bretaña impuso restricciones al comercio chileno internacional de salitre, con el fin de asegurar el abastecimiento nacional, especialmente para la fabricación de explosivos y municiones, pero también con el fin de impedir el suministro a las potencias enemigas.

\footnotetext{
${ }^{38}$ L. Vitale, op. cit., pp. 249-250.

${ }^{39}$ O. Hardy, op. cit., p. 62.

40 Ibid., pp. 62-63.
} 
Las medidas restrictivas británicàs llegaron hasta la imposición de un embargo comercial; como resultado de la promulgación por el Parlamento de una ley que prohibía a británicos (entonces en poder de casi el $90 \%$ de la actividad vinculada con el salitre) comerciar con terceros que hicieran negocios con el enemigo. Londres elaboró una lista de personas o compañias, en países neutrales, con las cuales se prohibía comerciar. Algunas de esas firmas de naturales alemanes que operaban en Chile fueron colocadas en esa lista $y$, como consecuencia, Chile vio afectado su comercio exterior.

La guerra en sí y sus efectos colaterales, que iban desde el cambio de prioridades políticàs, económicas y financieras para Gran Bretaña, así como la falta de transporte marítimo (hasta entonces cubierto en parte importante por la marina mercante británica); como así también la pérdida de los mercados europeos y la aplicación de las políticas comerciales de embargo, provocaron un aislamiento comercial de Chile y un vacío que fue cubierto rápidamente por los Estados Unidos.

Washington desplazó en 1915 a Gran Bretaña como principal socio comercial chileno (importaciones y exportaciones). Pero el país no abandonó su estrecha vinculación con Gran Bretaña.

En octubre de 1914, Chile concluyó un tratado comercial con Gran Bretaña, por el cual se comprometía a proveerle 680.000 toneladas inglesas de salitre y transportarlas en barcos de su propia marina de guerra hasta las costas de Estados Unidos.

La participación chilena en la producción mundial de abonos nitrogenados bajó de una posición de casi monopolio al $32 \%$, efecto que se reflejó en la contribución del salitre al presupuesto nacional, que descendió del $60 \%$ durante la guerra al $24 \%$ en 1919.

Después de finalizado el conflictó, el gobiemo chileno se asoció, aportando capitales y nuevas áreas de explotación, a las empresas salitreras inglesas, para implementar un nuevo sistema de elaboración, que permitiera recuperar los mercados perdidos, pero, en la práctica, el hecho de ser Guggenheim -empresa inglesa-el dueño de la patente, permitió a esa firma una participación superior a los mil millones de pesos, el control sobre las restantes compañías y también sobre el directorio de la Corporación de Salitres de Chile, una sociedad mixta, cuyo resultado fue el creciente endeudamiento de la Corporación con banqueros chilenos y norteamericanos, situación que aceleró el deterioro comercial y económico chileno, así como de la influencia comercial británica. La gran depresión y la crisis de los años treinta terminaron por desplazar definitivamente al salitre $-y$ por tanto al gran capital inglés- de su lugar 
preponderante en la economía chilena, en beneficio de Estados Unidos y el desarrollo de la gran minería del cobre. El proceso de deterioro se remontaba no obstante al inicio del gran conflicto europeo.

La Primera Guerra Mundial marcará la declinación gradual y progresiva de la influencia británica en América Latina y, desde luego, en Chile; cediendo paso a una era de hegemonía norteamericana.

Esta declinación no fue sólo económica; ella abarcó también los aspectos políticos y militares, espacio que sería cubierto por los Estados Unidos.

\section{Las relaciones con Estados Unidos.}

\section{1.- Una perspectiva general.}

El estudio de las relaciones entre ambos países puede abordarse desde diversas perspectivas, que marcan igualmente los signos de divergencia entre ambos, a lo largo de la historia.

Las relaciones entre Chile y los Estados Unidos fueron marcadas, durante un largo proceso histórico que se inicia con la independencia, primero por la competencia, donde sobresalen las tensiones y las disputas, y luego también coincidentes desde comienzos del siglo $\mathrm{XX}$-por la asimetría.

Durante el siglo XuX y hasta la Segunda Guerra Mundial, las divergencias se centran en el ámbito de las relaciones políticas interestatales; la rivalidad de ambos por la hegemonía en el Pacífico Sur. En cambio, a partir de la segunda post-guerra, las tensiones entre ambos se derivaron de los intereses económicos norteamericanos en Chile y de la creciente infiuencia de la potencia en el sistema socio-económico y político chileno. Como señalan dos autores, "el conflicto o la cooperación, que antes se expresaban en los lazos interestatales, cambiaron parcialmente de contexto y se reflejaron progresivamente en los vínculos transnacionales entre Estados Unidos y diversos actores del sistema politico.chileno". 41

Los aspectos que más identifican la perspectiva histórica de sus relaciones bilaterales han sido las tensiones y disputas, que -como afirmamos más arriba-se sustentaron durante un extenso período en la

${ }^{41}$ Heraldo Muñoz \& Carlos Portales, Una amistad esquiva. Las relaciones de Estados Unidos y Chile, (Santiago: Editorial Pehuén, 1987), p. 11. 
rivalidad: Evidentemente es posible comprender por qué Chile no ha constituido un punto de apoyo importante para las políticas latinoamericanas de Estados Unidos, ${ }^{42}$ así como entender las disputas en tomo a las concepciones y objetivos del panamericanismo y del sistema interamericano.

Sin embargo, con posterioridad a la Segunda Guerra Mundial, el impacto interno en la sociedad chilena de las políticas estatales y transnacionales generadas en Washington fue creciente, condicionando tanto la relación bilateral como el propio desarrollo interno de la sociedad chilena. ${ }^{43}$ Este cambio marca la transición desde la rivalidad a la dependencia y señala también la influencia excluyente de la potencia en la política, la economía y la sociedad chilenas.

Las relaciones de Chile con Estados Unidos comienzan en la década de 1820, pero sólo alcanzan su rasgo "interamericano" cuando Chile, luego de su triunfo en la Guerra del Pacífico (1879-1883), emerge como un poder subregional en ascenso cuyos intereses son percibidos por los Estados Unidos -dentro de su política hegemónica-como competitivos, en cuyo espectro las relaciones adquieren el rasgo conflictivo que las caracterizará hasta los años de 1.940.

Como señala Joaquín Fermandois, "Este encuentro coincide con la etapa naciente de máximo imperialismo de parte de Estados Unidos, y no es casualidad que entonces Chile sea víctima de una humillante irracionalidad, muy típica de las expansiones imperiales". 44

La respuesta chilena parece ser una línea de relativa resistencia a la hegemonía, con hitos como las posiciones neutralistas durantela Primera Guerra Mundial y, en especial, durante la Segunda Guerra hasta 1943.

A partir de las realidades emergentes de este último conflicto y dè la profunda asimetría de poder entre ambos actores estatales, Chile se integra en el marco de la Guerra Fría, donde sus intereses fundamentales serán congruentes con los del Sistema Interamericano, aun cuando ocasionalmente se dieran disonancias más o menos pronunciadas. ${ }^{45}$

En esta etapa, de vínculos transnacionales -caracterizados por las masivas inversiones privadas norteamericanas en la minería del cobreen el marco de una hegemonía global, se acentúan las situaciones de

\footnotetext{
${ }^{42}$ Ibid., p. 12.

43 Jbid.

44 Joaquín Fermandois, Chile y el mundo. 1970-1973. La politica exterior del gobierno de la Unidad Populary el Sistema Internacional, (Santiago: Ediciones de la Universidad Calólica de Chile, 1985), p. 251.

${ }^{45} \mathrm{Ibid}$.
} 
antagonismo político, que sin embargo nunca alcanzarán el nivel de ruptura.

Durante el período de la Unidad Popular (1970-1973), las relaciones bilaterales alcanzarán su más alto nivel de conflicto, abarcando tanto las relaciones interestatales como las transnacionales.

A partir del derrocamiento de Allende y la desintegración del régimen constitucional chileno (1973), las relaciones bilaterales se caracterizarian por el apoyo estadiounidense al régimen militar. Pero, a partir de 1987 las relaciones entre ambos gobiemos ingresaron en una etapa de amplias divergencias, particularmente derivadas de la situación de los derechos humanos en Chile, aun cuando los intereses norteamericanos se vieron ampliamente favorecidos por el proceso de transnacionalización y la política unilateral de apertura de la economía chilena.

$\mathrm{La}$ influencia norteamericana se manifiesta fuertemente en las Fuerzas Armadas, sobre todo a partir de 1945, "y en la identificación de Chile con el TIAR, al que se consideró pieza maestra de la defensa de la seguridad nacional (en su sentido restringido, es decir, como garantía de la intangibilidad de las fronteras) chilena". De igual forma, "las tensiones políticas que implicaba el esquema de Guerra Fría -así como la realidad sustantiva de Latinoamérica-hicieron que la doctrina tradicional de las Fuerzas Armadas, que de suyo lógicamente implicaba ya un anticomunismo latente, adoptara gradualmente una ideología anticomunista compartida en sus rasgos fundamentales con el Sistema Interamericano". 46 Esta influencia y las vinculaciones militares serán fundamentales durante la etapa del gobiemo militar: primero por el apoyo, luego como instrumento permanente de acceso a la cúpula de poder del régimen y vehículo de comunicación directa e influencia permanente sobre un actor político clave de la institucionalidad autoritaria y aún más allá de ésta.

Durante el mismo período se profundiza la inversión norteamericana en el país, especialmente en la gran minería del cobre. Sin embargo, los beneficios para Chile son bastante relativos. Tal como señalan los historiadores, hacia la segunda mitad de la década de 1960 se había llegado a una especie de saturación política por la acumulación de frustraciones en tomo a lo que supuestamente deberia haber dado a Chile la asociación con Estados Unidos en la gran minería del cobre. A partir de alli, el gobierno chileno, en dos oleadas sucesivas propondría una

${ }^{46}$ Ibid. 
legislación que culminaría en una virtual nacionalización de la gran minería del cobre, a lo que Estados Unidos no opuso mayor resistencia. ${ }^{47}$

Chile ingresa aceleradamente al entomo hegemónico norteamericano. De hecho la inversión y el comercio constituían los factores claves, pero a ellos se agregarían la influencia en las Fuerzas Armadas que, asociado a lo anterior, constituirían las vías más eficientes por las cuales la hegemonía norteamericana podía hacerse sentir, a partir de las decisiones de un "actor racional".

Tomadas en cuenta en conjunto estas "vías de influencia", la hegemonía norteamericana en Chile aparece como algo absolutamente evidente. Por una parte, las mismas reflejan y resaltan la capacidad de la influencia norteamericaria en Chile; por otra, aseguran argumentos politicos a programás y propuestas partidarias que apunten a despegar al país de tal nivel de influencia y dependencia.

Los Estados Unidos reaccionarían rápidamente a tales objetivos; por ello, desde comienzos de los años de 1960 decidieron impulsar lo que consideraron "gobiernos reformistas": primero el del conservador Jorge Alessandri (1958-1964) y luego el del democratacristiano Eduardo Frei (1964-1970); ambos con la idea específica de oponerlos a las fuerzas de izquierda que, desde los mismos años, propugnaban una completa nacionalización de la gran mineria del cobre y de otras empresas de capital norteamericano.

Esta decisión de "impulsar" determinadas candidaturas -y tal como se desarrolla más adelante-implicó en los hechos una amplia y progresiva estrategia de ingerencia en los asuntos internos chilenos. Al mismo tiempo, Chile se convertirá, en esos años, en el mayor recipiendario de ayuda económica (medida per cápita) en América Latina ayuda que comenzaría a decaer hacia finales de la misma década. ${ }^{48}$

\footnotetext{
${ }^{47}$ El programa presidencial de Eduardo Frei proponia la "chilenizaciön" del cobre; un acuerdo que convenia -desde la perspectiva gubernamental-a los intereses de Chile y de las empresas de la gran mineria, por el cual el Estado chileno adquiria acciones de las compañias, a cambio de cuantiosas inversiones para aumentar la producción y así mantener su posición en el mercado mundial de cobre. Por su parte, las empresas norteamericanas recibian beneficios tributarios por 20 años. Gracias a estos acuerdos - a los que se opuso la izquierda-las compañias norteamericanas se asociaron al Estado de Chile: Chile pasó a ser mayoritario en la mina El Teniente y minoritario en Minera Andina y en Exótica. Sin erabargo, el precio intemacional del cobre favoreció a las empresas norteamericanas, que financiaron sus nuevos aportes con las utilidades generadas por estos aumentos. Frei negoció nuevamente, proceso que terminó en 1969, por el cual el Estado adquiriỏ el $51 \%$ de las acciones de las subsidiarias de Anaconda (propietarias de "Chuquicamata" y "El Salvador"), a valor libro y a un plazo de 12 años, obteniendo una "opción de compra" del $49 \%$ restante, estimąio su valor sobre la base de las utilidades que anualmente genetaran estas sociedades.

${ }^{48}$ Ver, Joaquin Fermandois, op. cit.; H. Muñoz \& C. Portales, op. cit.; tambièn, Raúl Bernal-Meza, "Teorias, ideas politicas y percepciones en la política exterior chilena: 1970-1989", en: Raúl Bernaí-Meza (sel. y comp.), Politica, Integración y Comercio Intermacional en el Cono Sur
} 
No obstante estas "vías de hegemonia", se deben tener presente algunos hechos, acciones y políticas que permiten al menos matizar estas "pautas de subordinación-dependencia", ya que la política exterior del mismo período no expresa un similar nivel de subordinación. En efecto, el gobiemo chileno se opuso a la política de exclusión de Cuba del Sistema Interamericano; criticó con decisión la intervención en Santo Domingo; estableció vínculos políticos y económicos con la Unión Soviética y el bloque oriental y, finalmente, lideró un nuevo modus vivendi en las relaciones Estados Unidos-América Latina, con el "Consenso de Viña del Mar".

El período siguiente, bajo el gobierno de Salyador Allende, trastocará de manera brutal las relaciones bilaterales; no tanto por el lado chileno, cuyo gobierno se manejará con notable pragmatismo, especialmente durante los dos primeros años (1970-1972), sino por el lado norteamericano, actor del cual desaparece todo atisbo de racionalidad política, imponiéndose los criterios ideológicos predominantes desde la época dura de la Guerra Fría.

El arribo y la instauración de un modelo autoritario en lo político y neoliberal en lo económico, bajo el control de las Fuerzas Armadas (1973), cuenta con el apoyo, la simpatía y el respaldo norteamericano; período en el cual la restricción de las relaciones financieras interestatales será sustituida por una amplia red de relaciones transnacionales, apoyadas en el hecho que Estados Unidos separa los canales políticos de los económicos, pero, fundamentalmente, porque a excepción del periodo Carter-la Casa Blanca apoya la continuidad del régimen militar.

Durante todos los años de permanencia del gobierno militar, los Estados Unidos no tendrán como prioridad impulsar una salida democrática en Chile, sino preservar sus intereses, que justamente no pasan por acelerar la transición política.

Asi, la transición democrática chilena, iniciada al finalizar la década de 1980, nada le debe a la política exterior norteamericana A partir de 1990, las relaciones bilaterales han estado marcadas por el pragmatismo que ha caracterizado a la política exterior de la Concertación, la coalición gubernamental que conduce desde entonces los destinos políticos de la república.

De manera sintética, Heraldo Muñoz y Carlos Portales han destacado algunos factores explicativos para comprender lo que llaman como "la

Latinoamericano, (Mendoza: Universidad Nacional de Cuyo, Fac. de Cs. Ps. y Sociales-CERIAL, 1989), pp. 43-196. 
amistad esquiva" que se ha observado históricamente entre Estados Unidos y Chile. Estos son: "1) La existencia de una memoria histórica de dos potencias ascendentes y adversarias en lo que respecta a su influencia en América del Sur, cuyas respectivas proyecciones entraron en conflicto durante el siglo XIX y principios del siglo XX; 2) la existencia de intereses económicos norteamericanos en Chile, particularmente desde la segunda década del presente siglo, cuyo desarrollo chocaba con políticas y concepciones del desarrollo nacional chileno; 3) el surgimiento en Chile de elementos de una fuerte corriente cultural antinorteamericana que cubrió el espectro, político desde la derecha hasta la izquierda; 4) una actitud intervencionista por parte de Estados Unidos, encaminada a influir decisivamente en el proceso de cambios en el país, impulsándolo primero y previniéndolo después; y 5) el surgimiento en Chile de un proyecto militar-tecnocrático que favoreció el proceso de transnacionalización en el ámbito económico, cuya característica fundamental en el plano político -la persistencia de un autoritarismo personalista-entró en contradicción con ciertas orientaciones e intereses básicos de la política exterior estadounidense". 49

La importancia de las relaciones comerciales, financieras, ideológicas, militares y políticas de Chile con Estados Unidos, asociada a la permanente influencia norteamericana sobre las Fuerzas Amadas chilenas y los esfuerzos de Washington por influir en los procesos de cambios internos chilenos, previniendo el avance de la izquierda, impulsando los gobiemos de Jorge Alessandri (1958-1964) y más ampliamente el de Eduardo Frei (1964-1970), década que se caracteriza por poner a Chile como el mayor recipiendario per cápita de ayuda económica estadounidense en América Latina; así como oponiéndose tenazmente al gobierno de Salvador Allende (1970-1973), permiten sustentar la intención y capacidad de una política hegemónica practicada por Estados Unidos en Chile.

A pesar de esta política, la política exterior chilena, bajo los gobiemos de Alessandri, Frei y Allende, buscó recursos de acción de una relativa autonomía, aunque los márgenes de la misma resultaran a la postre ser bastante estrechos.

La década de 1990, en el marco de un nuevo orden mundial, con un país periférico integrado fuertemente -y de manera asimétrica- a la economía transnacional, ha visto surgir un pragmatismo político en Santiago, funcional a los intereses y objetivos derivados de la profunda

${ }^{49}$ H. Muñoz \& C. Portales, op. cit., p. 13. 
vinculación económica, comercial y financiera de Chile con Estados Unidos, política que se caracteriza por la ausencia de visiones globales y preconceptos.

\section{2.- La evolución histórica de las relaciones chileno-norteamericanas.}

La primera potencia que intenta una aproximación al naciente:Estado chileno son los Estados Unidos. El Cónsul Joel Poinsett es recibido en Santiago en febrero de 1812. Se trata de un impulsor teórico de los nuevos gobiernos de Santiago y Buenos Aires. ${ }^{50}$ Luego viene la visita del diplomático Theodorick Bland, un hombre opuesto a los patriotas, que


que hace el tránsito a Santiago desde Buenos Aires por tierrạ y otro que llega por mar, que Chile aparece como un relativo punto geopolitico de interés para Estados Unidos. En efecto, si bien la Misión Worthington (febrero de 1818) es la de un agente comercial, de carácter especial (commercial agents), su objetivo es político y comercial: obtener de Argentina, Chile y Perú reglamentos aduaneros liberales, exaltando en. ellos la conveniencia de desarrollar su respectivo comercio con los Estados Unidos. 51

Junto a éste, pero por mar, viene la Misión Prevost (en Valparaíso en enero de 1818). Ambos comisionados se reúnen en Santiago e intercambian sus impresiones sobre los asuntos del país y el curso de la política que debía observarse respecto del gobiemo chileno. Reseña Mr. Worthington que, "el magistrado Prevost me pidió que insistiera en la necesidad de que tengamos siempre buques de guerra en las aguas de estas provincias, y yo soy completamente de la misma opinión" 52

Las referencias de algunos historiadores a la correspondencia entre los primeros agentes norteamericanos en Chile con su Departamento de Estado, señalan claramente -y de una manera muy temprana-, la preocupación del gcbierno norteamericano por abrir el mercado chileno al comercio de ese país. ${ }^{53}$

\footnotetext{
${ }^{50}$ F.A. Encina y L. Castedo, Resumen de la historia de Chile, (Santiago: De. Zig-Zag, s.f. ) $_{2}$ p. 534. ${ }^{51}$ Yer, Ricardo Montaner Bello, Historia Diplomática de la Independencia de Chile, (Santiago: Editorial Andrés Bello, 1961), p. 43.

${ }^{S 2}$ Ibid., p. 44.

${ }^{53}$ Vale la pena citar al respecto los archivos correspondientes a los "Special agents dispatches". Un análisis de los mismos está en William R. Manning (ed.), Diplomatic correspondence of the United States the independence of the Latin American nations, (New York: 1925). Una traduccion del mismo aparece en Domingo Amunátegui Solar, Descripción económica y politica de Chile en el año de 1818, (Santiago: 1916). Ver, también, Charles W. Centner, op. cit.
} 
Worthington tendría una particular importancia en la posición que el Secretario de Estado John Quincy Adams tuvo respecto de Chile, que podría bien explicar la naturaleza profunda de la oposición del gobiemo norteamericano a reconocer su independencia. Fue este agente "comercial" el que proveyó de información a su gobiemo sobre la creciente vinculación que se iba dando entre Chile y Gran Bretaña. Sobre estas informaciones, Jeremy Robinson, agente especial del gobierno norteamericano, comunicó al Secretario de Estado, a principios de 1818, que la posición del comercio británico en el comercio exteriór chileno era de tal magnitud que era dificil que otro competidor (para el caso, los Estados Unidos); pudiera:tener éxito en desafiarlo. ${ }^{54}$ Puede concluirse en este sentido que el acercamiento norteamericano a Chile tuvo exclusivos intereses mercantiles.

Sin embargo, desde la óptica del paissudamericano, las relaciones de Chile con Estados Unidos fueron marcadas porkas primeras percepciones respecto de las luchas independentistas. Aunquè Portales fue extremadamente prudente (y receloso) en su visión de las ämbiciones de. Estados Unidos con respecto a Sudamérica, sus sentimientos sobrela falta de apoyo de Estados Unidos a Chile en sus luchäs contra España constituyeron la primera fuente concreta de hostilidad chilena hacia los Estados Unidos.

Lawrence Littwin ha reseñado, luego de este primer antecedente, varios acontecimientos que habrian afirmado posteriormente esta hostilidad. Entre ellos, señala las inatendidas solicitudes de apoyo para la causa libertadora; la negativa de reconocimiento oficial para Chile, por parte del Secretario de Estado John Quincy Adams, que argumentó "ausencia de un derecho moral a la independencia por parte de Chile"; la violación norteamericana al bloqueo chileno sobre la costa peruana (1.819); la política expansionista norteamericana sobre México y Centroamérica, durante la década de 1840; el abandono de apoyo durante la guerra contra España (1864), cuando los Estados Unidos retiraron su escuadrón naval de Valparaíso, permitiendo así el bombardeo del puerto por la escuadra española y, finalmente, la política antichilena seguida por Estados Unidos durante la Guerra del Pacífico (1879-1883). ${ }^{55}$ Como dice este autor, "Chile buscó a los Estados Unidos como su mejor amigo, y ese amigo había fallado en asistirlo en sus horas de necesidad". Esto

\footnotetext{
${ }^{54}$ Robinson a John Quincy Adams, 18 de febrero de 1823, Valparaiso, United States Department of State Archives, "Special agents dispatches", Vol. V; citado por Charles W. Centner, op. cit.

${ }^{55}$ L. Littwin, op. cit., pp. 46-48.
} 
culminó por producir un alejamiento; "para mitad de siglo (XDX), tanto en lo político como en todo lo demás, Chile estaba mirando hacia Europa". 56

Retomando el relato histórico, las relaciones entre ambos países adquirieron un perfil más cordial, luego de la etapa de neutralidad sui generis adoptada por Estados Unidos durante las luchas por la independencia, cuando este país reconoció a Chile como república independiente, en enero de 1832, aunque dicho acto no fue corroborado por la firma de un Tratado de Amistad, Comercio y Navegación; según el estilo, acto que recién se formalizaria dos años después.

El segundo momento importante de tensión se produciría durante la guerra de Chile contra la Confederación Peruano-Boliviana, cuando Estados Unidos, detrás de su declarada neutralidad, fue favorable a la Confederación. Este hecho representa la primera referencia de la rivalidad de Washington con Santiago, fundada en la desconfianza sobre el efecto del poderío que podría alcanzar Chile de salir triunfante en la guerra.

El tercermomento se da durante las décadas de 1840 y 1850 , derivado del apoyo chileno a México, en su conflicto con Estados Unidos y como consecuencia del trato vejatorio que recibian los chilenos en California, durante la época de la fiebre del oro.

Luego de la Guerra del Pacífico, que dejó a Chile como una potencia en el subsisteria del Pacífico en el Cono Sur, a la desconfianza se sumó la rivalidad. "El surgimiento de Chile como verdadera potencia en la América del Sur y el prestigio político internacional que había alcanzado en la segunda mitad del siglo XIX, encontraron franca oposición en los Estados Unidos, tanto en el gobierno como en algunos sectores de la opinión pública. La situación que se va a crear desde 1870 en adelante, llamaba a la práctica de una diplomacia astuta y auténtica. Sin embargo, el Departamento de Estado obró con un espíritu tan precario que hacía recordar las acciones del Coronel Barton". 57

Lo que algunos autores norteamericanos han illamado "el anti-nórtea" mericanismo chileno", 58 va a adquirir un abierto perfil de desconfianza hacia Estados Unidos con ocasión de los acontecimientos durante y posteriores a la Guerra del Pacífico. Durante esos años los Estados

\footnotetext{
56 Ibid, . F. 48.

${ }^{57}$ Cristián Guerrero Yoacham, "Chile y Estados Unidos: relaciones y problemas, 1812-1916", en: Walter Sánchez G. \& Teresa Pereira (eds.), 150 años de Politica Exterior Chilena, (Santiago: Editorial Universitaria, Instituto de Estudios Internacionales, 1977), p. 74.

${ }^{58}$ R. Burr, op. cit.; E. Davis, J. Finan \& F. Peck, op. cit.; L. Littwin, op. cit., enire otros.
} 
Unidos pasaron al menos por tres etapas en su posición respecto de Chile y su conflicto con Perú y Bolivia: 1) Impulsar gestiones de paz, sin intentar imponer sus propios puntos de vista (hasta marzo de 1881); 2) intervención abiertamente favorable a Perú y Bolivia, rechazando el derecho de Chile a extender su territorio por medio de la guerra o tomándolo como pago de reparaciones de guerra (hasta enero de 1882);3) limitar las actividades a intentos de mediación imparcial, sin buscar dictar los términos de la paz, llegando a aceptar la cesión del territorio de Tarapacá como compensación de guerra.

El cambio entre la segunda y tercera etapas se relaciona con la posición del Secretario de Estado Blaine y su reemplazo posterior. Blaine consideraba que Chile era pro-británico y que su victoria sobre Perú y Bolivia ayudaría al poderio inglés en Sudamérica, percepción que compartían los financistas norteamericanos que se oponían a la ocupación chilena del litoral peruano-boliviano.

A pesar de la posición adoptada por Washington en esta tercera etapa, los Estados Unidos volvieron en un momento a su posición pro-peruạa, uniéndose el representante norteamericano en Lima con los agentes de Francia, Italia y Gran Bretaña, que amenazaron a Chile con solicitar la intervención de esas grandes potencias. Sin embargo, aunque días después el nuevo Secretario de Estado rechazó el memorándum firmado por su agente, la ambigua política de Estados Unidos afectó por mucho tiempo las relaciones con Santiago; hecho muy comprensible si se toma en cuenta la situación de riesgo vivida por Chile al enfrentarse militarmente a dos de sus vecinos y teniendo que neutralizar la política belicosa de su tercero (Argentina).

Por otra parte, Estados Unidos había impulsado también el llamado a un "Congreso de Panamá", que se abocara a tratar las consecuencias del conflicto entre Chile y sus vecinos del norte.

Posteriormente los Estados Unidos intervendrian directamente en los acontecimientos internos de Chile, en particular durante la Guerra Civil de 1891 y luego con ocasión del incidente del "Baltimore" en el puerto de Valparaíso (16 de octubre de 1891), cuando argumentando ofensa a su nación, amenazaron a Chile con la intervención armada y la ruptura de relaciones. 59

\footnotetext{
${ }^{59} \mathrm{R}$. Burr, op. cit:; Peter Sehlinger, "Las armas diplomáticas de inversionistas internacionales durante la Guerra del Pacifico", en: Sánchez \& Pereira, op. cit., pp. 44-65; Cristián Guerrero Yoacham, "Chile y Estados Unidos: relaciones y problemas, 1812-1916", en: Sánchez \& Percira, op. cit., pp. 65-82; Mario Barros Van Buren, Historia Diplomática de Chile, (Santiago Editorial: Andrés Bello, 2a. edición actualizada a 1958), caps. XI a XIII.
} 
Sin embargo, a diferencia de los objetivos de las potencias europeas, en sus intereses e intervención en la guerra, la posición norteamericana se relacionaba más directamente con las percepciones de rivalidad hegemónica con Chile, en el ámbito del Pacífico Sur. En efecto, mientras las potencias europeas buscaban resolver los problemas de intereses finan-. cieros y comerciales perdidos, los Estados Unidos veían a Chile como un poder naval y económico rival en una zona hasta entonces alejada de las preocupaciones político-estratégicas.

Lo que hoy parece una fantasía ta de la rivalidad entre Chile y Estados Unidos-ha sido puesta en una interesante perspectiva histórica por Gonzalo Vial. Dice este autor. "Verdaderamente, lo que Estados Unidos temía era la rivalidad chilena en el Pacífico. Esto nos parece absurdo họ día, mirando ambos países con sus actuales dimensiones, pero no resultaba tan absurdo entonces y con las dimensiones existentes en esa época. Chile era, si exceptuáramos los Estados Unidos, la única nación americana políticamente organizada y estable. Habíamos exhibido hasta 1879 un progreso modesto, pero constante. Ahora, el salitre nos abría ilimitadas perspectivas económicas y otras tantas, suponían muchos (equivocadamente), el guano. Nuestra aptitud militar había quedado clara, y el Ejército chileno contaba con la aguerrida tropa, la oficialidad, la experiencia, la organización y las armas dejadas por el 79’. Más importante era todavía la escuadra nacional, incluyendo los blindados propios, el Huáscary los buques menores capturados al Perú. ¿Quién nos podía hacer militar y navalmente el peso en la costa pacífica? No los Estados Unidos, desde luego, cuya armada era muy inferior, aunque ahora lo hallemos increíble" 60

Los acontecimientos posteriores (desmembramiento de Colombia, la guerra de Estados Unidos contra España, que se agregaban a las actividades norteamericanas en Centroamérica), generaron en los grupos políticos y de poder chilenos un rechazo, que era la demostración de la oposición a lo que se consideraba una clara politica expansionista e imperialista de Estados Unidos.

La desconfianza, rivalidad y competencia entre ambos paises, pasó así a constituir parte de la memoria histórica de las relaciones entre los dos países, cuya incidencia se proyectaría hasta la mitad del siglo XX.

Para Chile, el principal fundamento en su percepción de rivalidad y competencia vis-à-vis los Estados Unidos se produce con el proyecto y

${ }^{60}$ Gonzalo Vial, Hisloria de Chile (1891-1973), (Santiago: Editorial Santillana, 1981), Vol. II, pp. 340-341. 
posterior apertura del canal de Panamá, que desplazaba a Valparaíso como puerto estratégico en el comercio marítimo entre Europa, el Pacífico y Asia.

La política norteamericana durante la primera década del sigo XX sustentada en el intervencionismo y la fuerte penetración económica, provocó el resentimiento de la cancillería chilena que buscaba equilibrar la balanza de poder con la potencia en el ámbito sudamericano del Pacifico. Chile apoya y confia en los planteamientos del Presidente Wilson. Sin embargo, los hechos y las acciones norteamericanas empañaron las palabras. Señala Cristián Guerrero que, "en suma, como lo ha dicho el notable historiador norteamericano Lloyd Mecham, las relaciones entre Chile y los Estados Unidos entre 1912 y 1916 se caracterizaron más por incidentes que por aspectos creativos, lo que es una prueba de la falta de bases políticas, sociales, culturales e ideológicas en los intentos de relacionarse entre ambas naciones. Este cuadro, que es válido hasta 1916, va a cambiar fundamentalmente después de la Primera Guerra Mundial" 61

A partir de 1915, los Estados Unidos pasaron a ser el mayor importador de productos chilenos y el mayor exportador hacia el mismo, una situación de dominio por sobre el comercio con Gran Bretaña que se iría consolidando con el transcurrir de la Primera Guerra Mundial. La dependencia de Chile con respecto a los Estados Unidos comienza a acentuarse como consecuencia de la guerra y otros acontecimientos no necesariamente vinculados a ella. En primer lugar, la apertura del Canal de Panamá (1914), que acortó en distancia y costo el transporte marítimo entre los puertos de la costa este norteamericana y la de los paises de la costa del Pacífico sudamericano; asi como la de los puertos de la costa oeste norteamericana respecto de los puertos chilenos, frente a los centros exportadores e importadores de Europa, con el consiguiente desplazamiento de Valparaíso. En segundo lugar, la Ley Federal de Bancos de los Estados Unidos, de 191.4, que autorizó a los bancos norteamericanos a abrir sucursales en el exterior y que posibilitó a los empresarios norteamericanos iniciar sus operaciones en Chile y otros países sudamericanos, ofreciendo a sus exportadores nacionales mejores facilidades para hacer negocios. Por último, se iniciaban las grandes inversiones norteamericanas en la minería del cobre, con lo cual ese país comenzaba a adquirir una enorme importancia en la vida económica y política de Chile, al tiempo que su mercado exterior del cobre quedaba atado a la demanda norteamericana.

${ }^{6 !}$ Cristian Guerrero Yoacham, op. cit., p. 82. 
El siguiente peldaño en los conflictos políticos entre ambos países se dio con ocasión de la neutralidad de Chile durante la Primera Guerra Mundial. Mientras los Estados Unidos se mantuvieron neutrales las cosas fueron fáciles. El problema se complicó para Chile cuanido los Estados Unidos entraron en la guerra, lo que obligaría a Chile a reconisiderar 'su política, aun cuando no cambiara su posición. El hecho que Estàdos Unidos tomara su decisión sin consultar a ningún país de América Latina, luego de haber recurrido al argumento del panamericanismo para impulsar en los países sudamericanos su propia política de neutralidad, constituyó para la cancilleria chilena una demostración más del desinterés con que Estados Unidos miraba la política exterior chilena.

A pesar de la neutralidad, la guerra confirmó la fuerte gravitación política y económica que entonces ya ejercían los Estados Unidos sobre Chile. La participación decisiva de Estados Unidos en la guerra había puesto de manifiesto que habría una supremacía de éstos en América Latina respecto de las potencias europeas y, en particular, de Gran Bretaña.

La posición de Estados Unidos se consolidó. "Ello llevó a Gran Bretaña a reconocer que América Latina estaba dentro de la zona de influencia de los Estados Unidos e imposibilitó que aquella nación pudiera implementar una ofensiva comercial destinada a amenazar la hegemonía ganada por esta República. Por supuesto, ya eran otros tiempos. Gran Bretaña fue la gran inversora en la industria del salitre, a fines del siglo XIX. Estados Unidos, en cambio, y desde principios de siglo $(X X)$, se encontraba invirtiendo en la industria del cobre, que pasaría a ser, desde la década de 1930, la principal fuente de exportación chilena" 62 Hacia 1920, los Estados Unidos ocupaban el primer lugar en el comercio exterior chileno, con un $54 \%$ del comercio nacional, mientras que $1 / 3$ de la inyersión extranjera de origen norteamericano, en América Latina, se encontraba en Chile. 63

Posteriormente se inicia el período de dependencia financiera. Desaparecido del escenario el tradicional proveedor de fondos (Londres), Chile habia visto cerradas sus fuentes de financiamiento extemo. La crisis de post-guerra acentuó las necesidades de recursos, por lo cual los gobiernos chilenos pusieron sus ojos e intereses en Washington. "Las

\footnotetext{
${ }^{62}$ Armando De Ramón, "Reseña al libro de J.R. Couyoumdjian, Chile y Gran Bretaña durante la Primera Guerra Mundial y la Postguerra, 1914-1921", Historia, Santiago, Instituto de Historia, Pontificia Universidad Católica de Chile, 1988, Vol. 33, pp. 495-496.

${ }^{63}$ Frederick Pike, Chile and the United States: 1880-1962, (Notre Dame, Indiana: University of Notre Dame Press, 1963), pp. 160-161.
} 
peticiones chilenas encontraron posteriormente acogida en-los círculos financieros de Nueva York y en 1921 el gobiemo contrató tres empréstitos en Estados Unidos por un total de US\$ 43.500.000; los primeros de una serie de préstamos a lo largo de la década".64 Más tarde, la crisis mundial de 1929-1930 "puso al descubierto otra de las. vinculaciones estructurales de la economía chilena con la norteamericana, ya que la deuda de Chile, además de ser una de las más altas del mundo, había sido contraída principalmente con entidades bancarias norteamericanas". 65

La inversión de capitales norteamericanos en la gran minería del cobre hizo aumentar intensamente la producción de mineral, desde fines del primer conflicto mundial, alcanzando las 321 mil toneladas en 1929. "Ese aumento se debió, especialmente, a la acción de compañías norteamericanas, que dejaron en un plano totalmente secundario a las antiguas empresas nacionales organizadas desde el siglo anterior. En 1925-1929, Chile ya contribuía con un 18 por ciento a la producción mundial de cobre, ubicándose inmediatamente después de Estados Unidos. Por otro lado, el cobre representaba un 40 por ciento del valor de las exportaciones chilenas". 66

Así, los Estados Unidos pasaban a ser el más importante mercado y proveedor de bienes y financiamiento para Chile, lo que fundaba las nuevas relaciones bilaterales basadas en la dependencia.

Esta dependencia tuvo su correlato en lo político, cuando Chile debió recurrir por ayuda a Estados Unidos para resolver la cuestión pendiente de Tacna y Arica con Perú, una gestión mediadora que había rechazado abiertamente treinta años antes y que ahora le crearia nuevas dificultades al país, por la posición favorable al Penú que asumirían, según la diplomacia chilena, los Estados Unidos.

Sin embargo, las relaciones de Chile con Estados Unidos no fueron mejores que en el pasado. Como señala Cristián Guerrero, "en la primera década del siglo XXX, el intervencionismo de los Estados Unidos en el continente y la fuerte penetración económica son los elementos básicos del accionar diplomático del Departamento de Estado. El justo resentimiento de la cancillería chilena y sus buenas intensiones de equilibrar en

\footnotetext{
${ }^{64} \mathrm{R}$. Couyoumdjian, "En torno a la neutralidad de Chile durante la Primera Guerra Mundial", en: W. Sánchez \& T. Pereira (eds.), op. cit., pp. 204-205.

65 José Morandé Lavin, "Chile y los Estados Unidos: Distanciamientos y aproximaciones", Estudios Internacionales, Santiago, Instituto de Estudios Intemacionales de la Universidad de Chile, Año XXV, No97, enero-marzo de 1992, p. 11.

${ }^{66}$ Celso Furtado, La economia latinoamericana. Formación histórica y problemas contemporáneos, (México: Siglo XXI Editores, 1969), p. 227.
} 
la medida de lo posible la balanza de poder, la lleva a auspiciar y creer en los planteamientos que hace el Presidente Wilson. Mas, antes de un año, las buenas palabras del mandatario quedaron olvidadas por sus acciones". 67

\section{Algunos ejes de divergencia.}

Según el historiador Frederick Pike, las élites políticas (los grupos de poder tradicionales chilenos) han desarrollado a través de la historia independiente tres tradiciones de origen político-cultural e ideológico, que han marcado las relaciones del país con los Estados Unidos: 1) una tradición antinorteamericana aislacionista, fundada en el espíritu y las cosmovisiones de Portales; 2) una tradición hispanoamericanista (que en la identificación de tendencias en la política exterior chilena hemos definido como "americanismo"); $y, 3$ ) una tradición del derecho internacional hemisférico. 68

En general, estas tres "tradiciones" se sintetizan en tres principios, la oposición al expansionismo (e imperialismo), el rechazo a la intervénción en los asuntos intemos de los Estados y la aplicación por Chile de determinados dogmas de derecho internacional a las relaciones interná-" cionales (que hemos identificado con el "idealismo") y que fundamentan el principio de igualdad entre los Estados, algo que el realismo político aplicado por Estados Unidos (y por cierto la estructura de poder del sistema internacional) hacen incompatible.

Vistas las relaciones bilaterales en un marco de expansión hegemónica, durante las tres últimas décadas del siglo XIX es evidente la política de competencia que ambós Estados practicaron entre sí por afianzar y mejorar su influencia en la costa del Pacífico sudamericano. Con el tiempo, esta competencia pasó a formar parte de la memoria histórica de las relaciones bilaterales: Según algunos autores, esto explicaría en parte la distancia que ha caracterizado los vínculos contemporáneos entre Santiago y Washington; una memoria histórica que derivó en lo que Pike y otros han denominado como la "cultura antinorteamericana", que se expandió entre diversos grupos sociales y políticos chilenos, desde conservadores y liberales, hasta radicales y socialistas. ${ }^{69}$

\footnotetext{
${ }^{67}$ Cristián Guerrero Yoacham, "Chile y Estados Unidos: relaciones y problemas, 1812-1916", op. cit., p. 82.

${ }^{68}$ F. Pike, op. cit.

${ }^{69}$ H. Muñoz \& C. Portales, op. cit.. Explicando las diferencias entre el. "antinorteamericanismo de izquierda y derecha", estos autores señalan que "si bien es cierto que en la derecha ha existido un fuerte sentimiento cultural antinorteamericano, ello no significa que aquélla no se haya aliado a
} 
En el ámbito hemisférico, desde fines del siglo XIX, las divergencias se centraron en torno a las distintas concepciones del "panamericanismo"; uno que era funcional a los intereses hegemónicos de los Estados Unidos $\mathrm{y}$; otro, con el cual los países hispanoamericanos $\rightarrow$ Chile en particular-buscaban asegurar su soberanía política. A partir de mediados de la década de 1910, Chile inició lo que por años sería -a ojos de autores como Pike- una activa política de liderazgo en la condena de todas las manifestaciones de expansión de la influencia de Estados Unidos en América Latina.

La política de Woodrow Wilson hacia América Latina confirmaria los temores de Chile, en particular la ocupación de Veracruz, en abril de 1914, y luego sus esfuerzos por establecer un Pacto Panamericano ;.yisto por Chile y otros Estados como un instrumento de intervención;e: imperialismo. Estos temores fueron compartidos por otros países latinoamericanos, en especial Argentina y Brasil.

Fue justamente la política de Washington la que generó entre estos tres países latinoamericanos su primera estrategia de concertación política trilateral, con la constitución del "ABC", cuyo objetivo de corto plazo fue mediar en el conflicto que generaba la ocupación de territorio mexicano por tropas estadounidenses, pero que, a más largo plazo, ubicaba a estas tres naciones como un supuesto pilar-clave por la dimensión relativa de ellas-de independencia de la región vis-à-vis los Estados Unidos, al tiempo que generaba una fuerza de equilibrio al poderío y la influencia de la potencia en América del Sur. En particular, la constitución del $\mathrm{ABC}$ buscaba la formación de un frente común contra el modelo panamericano de Wilson. Sin embargo, la ilusión de que el Pacto del $A B C$ se transformara en un mecanismo apto para mejorar la posición negociadora de América Latina frente a Estados Unidos fracasó, cuando al producirse el ingreso de Estados Unidos a la Primera Guerra Mundial, Brasil siguió a la potencia, declarando la guerra a Alemania, con lo cual la posición común de neutralidad sufriría un revés que acentuaría la posición de debilidad de los otros actores respecto de Washington.

menudo con Washington. La vinculación real entre la derecha chilena y Estados Unidos se explica por el hecho que tradicionalmente la política norteamericana ha servido de apoyo a la derecha en sus intentos de mantener el status quo, y que los líderes de derecha han tendido a soslayar su aversiön cultural e intelectual respecto a la sociedad norteamericana a cambio de los beneficios materiales y concretos que se originan en una estrecha asociación con una potencia capitalista desarrollada. Cuando Estados Unidos ha promovido el cambio, esos sentimientos culturales han afforado". Jbid., p. 32. 
Evidentemente que la posición de Chile en el ámbito de lạs Conferencias Panamericanas, 70 abogando por un "código de Derecho Intemacional Americano" que abordara los principios de absoluta igualdad entre las naciones y. el de no intervención en los asuntos intemos de otros Estados, se basaba en su tradición de política exterior fundada por el pensamiento de Portales y Bello.

La recurrencia al derecho se asienta en la idea de Bello de que la legalidad (tratados, principios, Derecho Internacional en definitiva) era un mecanismo eficiente para defender al país pequeño; por lo tanto, la posición chilena frente al panamericanismo fue coherente.

Pero habia otra lectura asociada a ésta; que un orden interiacional, basado en la ley y el derecho, permitia a una nación débil participar junto a los fuertes en la construcción de un sistema internacional basado en el derecho y que en él Chile podía asumir un liderazgo.

Desde este punto de vista, había dos paradigmas que sustentaban la visión de Chile sobre el sistema internacional, que se enfrentaban a los paradigmas norteamericanos de politica exterior hemisférica: Santo Tomás vs. Hobbes y "la fuerza del derecho" vs. "el derecho a la fuerza". Dice Littwin al respecto, "... debería ser evidente que la política exterior chilena, cuya referencia primaria es la ley, es el producto de una cultura condicionada por el pensamiento legal. Cuando el último ministro de relaciones exteriores del presidente Jorge Alessandri, Julio Philippi, sostiene que es un tomista, quiere decir que es consciente de una tradición cultural nacida del pensamiento católico medieval e implantado en su mente por los procesos de culturización de su sociedad. Implica que los chilenos pueden sostener delante de sí la imagen utópica de un universo ordenado en un mundo que es caótico o que está amenazado por el caos. Puede relegar el estado de naturaleza hobbesiano, en el cual una nación como Chile carece de poder, al reino de la imperfección humana. Al tratar de instituir un contexto de ley etemamente sancionada, no sólo provee de la posibilidad de alcanzar un estado de gracia, sino que puede obviar el estado de naturaleza y capacitar al débil para morar con los fuertes en una condición de armonía funcional tomística. La función de Chile en esta utopía sería liderar en la construcción de un edificio legal". ${ }^{71}$

\footnotetext{
${ }^{70}$ Dos análisis sobre el sistema interamericano, en una perspectiva histórica, de donde se pueden extraer las distintas interpretaciones y politicas seguidas tanto por los Estados Unidos como por Chile y otras naciones latinoamericanas, se encuentran en Alberto van Klaveren "Antecedentes históricos del sistema interamericano", en: Rodrigo Díaz Albónico (ed.), Antecedentes, balance y perspectivas del Sistema Interamericano, op. cit., pp. 18-55; y, Hugo Llanos Mansilla, "Panorama histórico de las relaciones internacionales entre Estados Unidos y la América Latina", Ibid., pp. 56-86.
}

${ }^{71}$ L. Littwin, op. cit., pp. 13-14. 
La situación de las relaciones entre ambos países cambió al iniciarse el siglo XX, que marcaría el ascenso hegemónico de los Estados Unidos y la declinación del poder de Chile. Al momento de la Primera Guerra Mundial el desequilibrio en desarrollo económico, industrial, científico y cultural entre ambos países era ya demasiado evidente.

Lawrence Littwin ha señalado, que "cuando la guerra finalmente terminó, Chile se enfrentó con dos problemas en la continuación del desarrollo de su política exterior. Un problema era que aunque los períodos de pre-guerra y de guerra habían engendrado una animosidad aumentada hacia los Estados Unidos, dicho país emergió de la guerra como el mayor inversor individual en la economía: chilena. El aislacionismo basado solamente en la hostilidad y en la elusión no podía enfrentarse ahora con el hecho de la influencia yanqui en Chile. El segundo problema, vinculado al primero por el rol de los Estados Unidos como mediador, era que la disputa fronteriza chilena con Perú y Boliviá 72 por Tacna-Arica todavía no estaba solucionada". ${ }^{73}$

\section{3.- Política y economía durante la hegemonía:}

La hegemonía norteamericana sobre Chile y su zona de influencia se relaciona directamente con el proceso de declinación del poder chileno, a fin del siglo XIX y comienzos del XX. A partir de este momento, las relaciones bilaterales comenzarán lenta, pero progresivamente, a transitar desde lo interestatal a lo transnacional. Comienzan a profundizarse las inversiones norteamericanas en Chile, al mismo tiempo que el comercio bilateral adquiere creciente importancia, hasta llegar a la Primera Guerra Mundial, cuando los Estados Unidos desplazarán a Gran Bretaña como el principal socio comercial de Chile. El siguiente cuadro da una visión del proceso de crecimiento del comercio bilateral durante el decenio de 1910.

\footnotetext{
${ }^{72}$ En realidad, aqui el historiador norteamericano comete un error. Para esa época, según el derecho internacional, no existía ningún problema fronterizo o limítrofe entre Chile y Bolivia, ya que la situación derivada de la guerra y del Pacto de Tregua de 1884 habia sido resuelta definitivamente por el Tratado de 1904. Por otra parte, ni Tacna ni Arica habian formado parte del territorio boliviano, sino del Perú.

${ }^{73}$ L. Littwin, op. cit., pp. 75-76.
} 


\section{Chile: exportaciones e importaciones a Estados Unidos como porcentaje del comercio total}

\begin{tabular}{|c|c|c|}
\hline$A \tilde{n} o$ & Importaciones & Exportaciones \\
\hline 1913 & 16.7 & 21.0 \\
\hline 1914 & 20.5 & 36.8 . \\
\hline 1915 & 33.3 & 42.9 \\
\hline 1916 & 42.4 & 49.9 \\
\hline 1917 & 49.0 & 64.4 \\
\hline
\end{tabular}

Paralelamente, Estados Unidos comienza también a ser el principal proveedor de financiamiento externo. La situación de dependencia financiera va a adquirir un rasgo constante a paitir de la crisis de 1929-1930, cuando Chile llega a ocupar uno de los primeros lugares en el endeudamiento extemo per cápita del mundo, deuda contraída fundamentalmente con entidades bancarias norteamericanas. ${ }^{75} \mathrm{Al}$ mismo tiempo, los Estados Unidos comenzaban a aplicar una serie de medidas proteccionistas que afectaban en particular a las exportaciones chilenas.

La enorme influencia alcanzada por los Estados Únidos en la región -y en Chile-a partir de 1917 y hasta 1941, puede percibirse a la lectura de los acontecimientos y la posición de América Latina respecto de los dos conflictos mundiales.

Durante la Primera Guerra Mundial, se hace evidente que la declinación del poder relativo chileno -poder alcanzado como consecuencia de los acontecimientos derivados de la Guerra del Pacífico- constituía vis-à-vis los Estados Unidos una competencia perdida para Chile. Esta realidad afectó las percepciones de las clases dominantes chilenas y, por ende, las relaciones con la potencia.

La situación comercial y financiera chilena frente a los Estados Unidos, la política norteamericana hacia América Latina y la ingerencia que comenzaba a manifestar en los asuntos intemos chilenos (oposición a Ibáñez, amenazas contra la República Socialista de los Cien Días, etc.), comenzaron por generalizar una percepción común a amplios sectores de la sociedad chilena, la cual veía a los Estados Unidos como una potencia imperialista.

\footnotetext{
${ }^{74}$ Fuente: R. Couyoumdjian, "En tomo a la neutralidad de Chile durante la Primera Guerra Mundial", op. cit.

${ }^{75}$ H. Muñoz \& C. Portales, op. cit., p. 40.
} 
El segundo cảmbio significativó en las características de la dependencia chilena y la hegemonía norteamericana, se produjo durante e inmediatamente deșpués de la Segunda Guerra Mundial.

El gobiemo chileno fue presionado en forma directa e indirecta a romper relaciones con el Eje. A través de conductos diplomáticos y políticos, Washington pidió a Chile alinearse a la posición norteamericana; mientras que, indirectamente, a través del naciente sistema (de consultas) interamericano, buscaba que Chile siguiera la posición de toda América (con la excepción de Argentina).

Durante el conflicto, los Estados Unidos imponen unilateralmente un precio determinado a las exportaciones de cobre.: Según un autor, esta medida significó para. Chile pérdidas por unos mil cien millones de dólares por concepto de menor precio de venta y de aproximadamente novecientos millones de dólares por impuestos no recaudados. 76

El otro aspecto de este cambio -en realidad una profundización de la dependencia- fue la complementación de la ayuda económica con crecientes lazos político-militares. Los Estados Unidos pasaban a ser -con la incorporación de Chile al TLAR y la aceptación por el gobiemo de Santiago de la definición de sus marcos globales de la política exterior, en el contexto de la Guerra Fría- el actor externo más relevante para Chile.

Sin embargo, durante todo el periodo "duro" de la Guerra Fría y luego a partir del triunfo de la Revolución Cubana.y su efecto sobre el sistema interamericano (desde el aislamiento del régimen castrista hasta las presiones de Estados Unidos en la O.E.A. para obtener la expulsión de Cuba), período en el cual las relaciones de Estados Unidos con América Latina se hacen profundamente complejas y conflictivas a pesar:del alineamiento, no faltaron las posiciones antagónicas en la política exterior chilena.

La paradoja se advierte, no obstante, en la medida que los gobiernos chilenos se oponen a la política norteamericana con respecto a Cuba, el sistema interamericano y las relaciones con el Caribe (invasión de Santo Domingo), mientras simultáneamente șe incrementan por parte de Washington la asistencia financiera, crediticia y la ayuda militar. Esta última comenzaba a justificarse a medida que las Fuerzas Armadas pasaban a ser -dentro del paradigma de la "seguridad nacional norteamericana"-

\footnotetext{
${ }^{76}$ Ver, Alexander Sutulov, "Evolución de la politica nacional del cobre y sus consecuencias en las relaciones con Gran Bretaña y EE.UU.", en: W. Sánchez G. \& T. Pereira, op. cit., p. 240.
} 
un actor clave, a través del cual se irían orientando las relaciones y la política intema y externa chilena.

Así, mientras el gobierno de Carlos Ibáñez del Campo (1952-1958) recibe en asistencia económica 69,1 millones de dólares y 34 millones de dólares en asistencia militar, estos valores alcanzan a 447,7 millones y a 80,9 millones, respectivamente, durante el período de la administración de Jorge Alessandri (1958-1964). En el aumento de créditos del Eximbank, las cifras pasan de 50,7 a 150,7 millones, entre los mismos periodos. En términos relativos, el aumento es del $8 \%$ al $13 \%$ de la asistencia económica total al continente latinoamericano, un incremento del $12 \%$ al. $13 \%$ en la asistencia militar y un aumento del $4 \%$ al $12 \%$ en la participación en los créditos del Eximbank. Sin embargo, durante el periodo de la administración de Eduardo Frei Montalva (1964-1970), las cifras de la ayuda bilateral ya marcan lo contradictorio de las relaciones interestatales: si bien en 1965 Chile recibe ei 15,3\% de la asistencia económica a América Latina y el 5,7\% de los créditos del Eximbank (que en 1960 habían representado el $12,5 \%$ y el $0,5 \%$, respectivamente), para 1967 la asistencia económica bajó al 3,8\% de la enviada a América Latina, reducción que se reemplaza por el $49,3 \%$ de los créditos del Eximbank, declinando al $10,9 \%$ y $4,7 \%$ en 1968 , respectivamente, y al 4,3\% de la asistencia económica, desapareciendo los créditos del Eximbank en 1970.77

Paralelamente, mientras la imagen de Chile sirve a la politica bemisférica de Washington, presentando al sistema politico chileno como el paradigma latinoamericano vis-à-vis el régimen cubano, la ingerencia norteamericana en los asuntos intemos chilenos se va profundizando, en particular en la medida que Washington se opone a cualquier posibilidad de gobierno de la izquierda chilena; pero en cuyo peligro también comienza a involucrar a un importante sector de la Democracia Cristiana, el partido de gobierno de Frei Montalva.

La ingerencia en los asuntos políticos internos chilenos se va a producir de manera indirecta y directa. De la primera lo que aparece como más evidente es el fortalecimiento de los lazos militares, que se afianzaban en la común percepción sobre el tipo de preocupación que imperaba en las escuelas militares interamericanas y que va siendo aceptada por

\footnotetext{
${ }^{77}$ Fuente: Yer H. Muñoz \& C. Portales, op. cit., pp. 69 y 71; también, Raúl Beraal-Meza, "Teorias, ideas politicas y percepciones en la formulación de la politica exterior chilena: 1.945-1987", en: $R$. Bernal-Meza, J.C. Puig \& L. Tomassini, et. al., Teorias de Relaciones Internacionales y de Derecho Internacional en América Latina, (Caracas: Universidad Simón Bolivar, Instituto de Altos Estudios de América latina/ O.E.A., 1989), Segunda Parte.
} 
las Fuerzas Armadas chilenas. El gobiemo de Alessandri recibe el $13 \%$ del total de ayuda militar otorgado al continente; se intensifica el entrenamiento militar contrainsurgente y comienza el equipamiento y entrenamiento de la policía de Carabineros en contrainsurgencia urbana. Esta intensificación de las relaciones militares y policiales se iba a expresar en los períodos siguientes en la intervención de las Fuerzas Armadäs y de Carabineros en la arena política. ${ }^{78}$ Según el Covert Action in Chile; del U.S. Senate, el 19 de julio de 1964, los altos mandos de las Fuerzas Armadas chilenas propusieron a Alessandri un golpe de Estado si triunfaba Allende en las èlecciones presidenciales de ese año. ${ }^{79}$ Posteriormente, entre 1970 y 1973, antes del golpe de Estado definitivo contra Allende, las Fuerzas Armadas chilenas lo intentarian en dos oportunidades, para, finalmente a partir de 1973, tomar el control de todo el sistema político chileno durante 17 años.

La ayuda económica comenzaba a constituir un factor fundamental de influencia de los Estados Unidos en el sistema político chileno. Durante los seis años de gobierno de Frei, éste recibió 45,6 millones de dólares por este concepto, mientras que bajo Allende, en sólo tres años, el país recibinia 33 millones, incrementándose la participación chilena en los programas de ayuda militar a América Latina al 13\%.

Los antecedentes de intervención directa han sido reportados por el informe ya señalado del Senado de los Estados Unidos. De los datos más relevantes pueden señalarse entre otros: otorgamiento de 2,6 millones de dólares a la candidatura de Frei (1964) y financiamiento de un parte importante de esa campaña presiđencial. 80 "Seymour Hersh sostiene que este financiamiento por parte de Estados Unidos habría alcanzado cifras aún superiores, si se toma el período 1963-1964, y que dicha candidatura recibió, además, apoyo de un grupo de corporaciones estadounidenses conformado por David Rockefeller en 1963 y conocido como Business Group for Latin America" 81 En junio de 1965 se descubre en Chile el "Plan Camelot", proyecto que buscaba aislar los factores capaces de inducir cambios revolucionarios en los países en desarrollo, proyecto Ilevado a cabo por un equipo de la American University, respaldado por el Departamento de Defensa de los Estados Unidos. ${ }^{82}$ Antes de las

\footnotetext{
${ }^{78}$ H. Muñoz \& C. Portales, op. cit.s p. 63.

${ }^{79}$ U.S. Senate, Covert Action in Chile: 1963-1973, (Washington: U.S. Government Printing Office, 1975), pp. 17-18.

${ }^{80}$ Ibid., p. 9.

${ }^{81}$ H. Muñoz \& C. Portales, op. cit., p. 65.

82 Ibid., p. 66.
} 
elecciones presidenciales de septiembre de 1970, la CIA, en colaboración con varias empresas transnacionales lideradas por laITI, participaron en acciones para impedir el triunfo de Allende. La ClA gastó cerca de un millón de dólares en esas actividades. 83 "El 15 de septiembre, el Presidente Nixon informó al Director de la CIA, Richard Helms, que un régimen de Allende en Chile no sería aceptable para los Estados Unidos e instruyó a la CIA a desempeñar un papel directo en organizar un golpe de Estado militar en Chile para prevenir la ascensión de Állende a la presidencia". ${ }^{84} \mathrm{El}$ plan incluyó actividades encubiertas de orden político, económico y de propaganda, así como apoyo a los militares chilenos a actuar contra Allende. ${ }^{85}$ Estas actividades culminaron con el asesinato del Comandante en Jefe del Ejército.

A partir del momento en que Allende tomó ocupación del cargo presidencial, la política norteamericana tuvo dos caras: una diplomática, formal, con una severa restricción de la ayuda externa, y otra de gran actividad encubierta. La misma incluyó ayuda financiera a los partidos políticos de la oposición, campañas de propaganda antigubernamental y apoyo a organizaciones del sector privado. Paralelamente se incrementaba la ayuda militar. Esta política de intervención directa se extendió más allá del dỉa del derrocamiento de Allende, la que incluyó acciones para mejorar la imagen interna e internacional del régimen militar, ayuda técnica y política a la Junta Militar para la implementación de las nuevas políticas; la aprobación del Comité de los 40 para la compra de una estación de radio anti-izquierdista, el financiamiento de viajes al exterior para campañas de apoyo a la Junta; colaboración de la CIA para la preparación del plan económico del primer período y asistencia a la Junta para la preparación del Libro blanco sobre el cambio de gobierno en Chile 86 y otras acciones. ${ }^{87}$

Los vínculos militares fueron el nexo clave del sistema de relaciones políticas bilaterales durante el régimen militar de Pinochet. Si bien se redujeron los aportes y se limitaron los vínculos oficiales por efecto de la enmienda Kennedy, las relaciones de carácter informal fuerón tanto o más importantes y constituyeron un mecanismo que dejaba abierto canales de comunicación política entre Washington y Santiago, a pesát

\footnotetext{
${ }^{83}$ U. S. Senate, Covert Action in Chile, op. cit., pp. 12-13.

${ }^{84}$ bid., p. 23.

${ }^{85}$ Ibict, también H. Muñoz \& C. Portales, op. cit.

${ }^{86}$ Publicado en Santiago, con posterioridad al golpe militar, en el cual se justificaba el derrocamiento del presidente constitucional.

${ }^{87}$ U.S. Senate, Covert Action in Chile, op. cit., pp. 30-61.
} 
de la politica oficial norteamericana en contra de la violación de los derechos humanos en Chile.

Más allá de la dependencia y la hegemonía, la política exterior chilena durante el período democrático anterior al golpe militar buscó espacios de autonomía. Las políticas exteriores de los gobiernos de Alessandri y Frei no siguieron el derrotero ideal imaginado por Washington, en la medida que Santiago se distanciaba cada vez más de la política hemisférica e interamericana de la Casa Blanca. Finalmente, la política interna de transformaciones socio-económicas impulsada por el gobierno democratacristiano terminó por ser vista como pro-izquierdista por la admiristración Nixon.

Los temas básicos de oposición de Chile se centraron en torno a la política norteamericana contra Cuba (Alessandri); la invasión de Santo Domingo; las propuestas de reforma de la OEA, para dar prioridad a los asuntos económicos por sobre los aspectos de la seguridad y, finalmente, el impulso del "Consenso de Viña del Mar", que planteó abiertamente la progresión contradictoria entre los intereses de los países latinoamericanos y los intereses estadounidenses; la progresiva normalización de relaciones comerciales con La Habana y el acercamiento de Chile hacia los países de Europa oriental, incluyendo relaciones comerciales y de cooperación con la Unión Soviética; todas acciones y políticas llevadas a cabo bajo el gobiemo de Frei. Como han señalado dos autores, "el gobiemo de Frei, que había sido considerado como un punto de apoyo clave a la estrategia regional de Estados Unidos, terminó,constituyéndose en un verdadero obstáculo al encabezar el desafio que el."Consenso de Viña del Mar" puso a la política exterior norteamericana, situando a Chile en la categoria de país problemático para Washington a comienzos de la década del 70".88

Con la llegada de Salvador Allende a la Presidencia de Chile, las relaciones bilaterales fueron trastomadas radicalmente por las percepciones y la animaversión de Washington.

Los problemas en las relaciones bilaterales se situaron a dos niveles: en el ámbito estatal y en el transnacional. En el primer escenaric, la política abierta de Washington fue su clara oposición a Allende y la disposición a hacer fracasar cualquier intento de éste por llevar adelante su programa de gobierno. En el segundo, las dificultades surgieron tanto a partir de la política de las compañias norteamericanas contra el programa de la Unidad Popular, sin importar las formas o mecanismos de

${ }^{88}$ H. Muñoz \& C. Portales, op. cit., p. 73. 
negociación para la aplicación del programa de nacionalizaciones, como por los efectos de la aplicación del plan de gobiemo. Como consecuencia, "las discrepancias en materia de política internacional entre ambos países, y la forma en que las políticas del gobiemo afectaron a los intereses norteamericanos, sólo reforzaron la orientación que había sido decidida con anterioridad a la ascención de Allende al cargo de Presidente" 89

Un autor norteamericano ha sintetizado con las siguientes palabras la politica seguida por Washington frente a Chile: "Nuestra participación. en Chile durante los años de Allende ha sido descrita como desestabilizadora. La administración Nixon utilizó una extensa variedad de tácticas económicas, financieras y encubiertas en su campaña para causar intranquilidad en Chile y promover la incertidumbre dentro del régimen de Allende. En respuesta a la nacionalización de propiedades norteamericanas en el área del cobre y a la negativa de Allende a pagar una compensación justa, la administración Nixon disminuyó la ayuda exterior a Chile y utilizó su poder de veto en las instituciones multinacionales para denegar préstamos claves al gobiemo. La administración Nixon también dificultó a Chile la obtención de vitales repuestos para mantener, sus fábricas y su sistema de transportes. Además, en los tres años en que Allende estuvo en el poder, los Estados Unidos invirtieron alrededor de 7 millones de dólares para apoyar a los periódicos y organizaciones opositores. Finalmente, las investigaciones recientes de la administración Nixon revelan que funcionarios de la Casa Blanca iniciaron una variedad completa de operaciones encubiertas, incluido el apoyo para el asesinato contra líderes chilenos, soborno a los políticos de la oposición y activo fomento de las conspiraciones para derrocar al gobierno". 90

Es evidente que en la política norteamericana hacia el gobierno de Allende primaron las percepciones y posiciones preconcebidas de Washington, lo que llevaba a que fuera cual fuera la política seguida por Santiago, el resultado iba a ser el mismo. La visión predominante en la Casa Blanca fue la del Asesor para la Seguridad Nacional, Henry Kissinger, para quien Allende iba a representar problemas para Estados Unidos en todos los órdenes, así como masivos problemas para la estabilidad regional y la imagen y posición de Estados Unidos en todo el hemisferio occidental. ${ }^{91}$ Posteriomente, en sus White House Years,

\footnotetext{
${ }^{89}$ Ibid., p. 75.

${ }^{90}$ Michael J. Kryzanek, Las estrategias politicas de Estados Unidos en América Latina, (Buenos Aires: Grupo Editor Latinoamericano, 1987), p. 112.

${ }^{91}$ U.S. Senate, Multinational Corporations and United States Foreing Policy, Hearings before the Subcommittee on Multinational Corporations of the Committee on Foreing Relations United States Senate, 93rd. Congress, Washington GPO, 1973, Part 2, pp. 542-543.
} 
Kissinger resumió de esta manera la política de Washington, seguida a partir de estas percepciones: "...la elección de Allende era un desafio a nuestro interés nacional. No podíamos reconciliarnos fácilmente con un segundo estado comunista en el Hemisferio Occidental. Estábamos persuadidos que pronto estaría incitando políticas antinorteamericanas, atacando la solidaridad del hemisferio, haciendo causa común con Cuba, y antes o después, estableciendo estrechas relaciones con la Unión Soyiética. $Y$ esto era aún más penoso porque Allende representaba una ruptura de la larga historia democrática de Chile y sería presidente no como una auténtica expresión de la mayoría sino como una casualidad favorable del sistema político chileno. El treinta y seis por ciento del voto popular no era realmente un mandato para la transformación irreversible de las instituciones políticas y económicas de Chile que Allende estaba decidido a efectuar".

"Las anteriores administraciones norteamericanas habían llegado a la misma conclusión. Dos administraciones habían juzgado que un gobierno de Allende en Chile estaría en contra de los intereses fundamentales norteamericanos? Nuestra conclusión en 1970 fue sustancialmente la misma" Másadelante agrega: "Lo que nos preocupaba acerca de Allende era su proćlamada hostilidad a los Estados Unidos y su patente intención de crear efectivamente otra Cuba. Era su programa explícito, y en verdad su antiguo objetivo, establecer una dictadura irreversible y un desafio permanente a nuestra posición en el Hemisferio Occidental (...): Nuestra preocupación por Allende estaba basada en la seguridad nacional, no en la economía". 92

Se aprecia así que en Washington lo que primó fuè la visión preconcebida de lo que sería un gobiemo de izquierda en Chile y su política internacional. Estados Unidos mantuyo una permanente actitud hostil e inflexible.

Como consecuencia, el derrocamiento de Allende constituyó el evidente objetivo de Washington: impedir la materialización del proyecto político y económico del gobiemo de la Unidad Popular.

Sin embargo, un elemento más vino a afectar estas relaciones: el rol de Chile, como un actor pasivo, en el "nuevo diseño de la primacía" norteamericana en el juego de poder mundial. En efecto, en el diseño del nuevo "orden legítimo" que tenía como objetivo de política mundial la dupla Nixon-Kissinger, Santiago constituiría un case-test de la política

${ }^{92}$ Henry Kissinger, Mis Memorias, (Buenos Aires: Editorial Atlántida), 3* edición, 1979, pp. 456-457. 
global norteamericana vis-à-vis la Unión Soviética y China. La reducción de costos de confrontación implicaba el cambio de instrumentos de la primacía: menos intervenciones militares abiertas y más acciones encubiertas, en las áreas de excluyente hegemonía. ${ }^{93}$

La intervención norteamericana en Chile continuó bajo el gobiemo militar, pero ahora como ayuda a la política de Santiago.

El gobierno norteamericano, Washington y el poder económico miraron complacidos el desenlace de los acontecimientos de septiembre de 1973. Sin embargo, poco a poco, el impacto internacional de la política sistemática de violación de los derechos humanos y civiles aplicada por el gobierno militar chileno provocó una creciente incomodidad en las esferas del poder. En particular, el asesinato en Washington del ex canciller de Allende, Orlando Letelier y su secretaria, de nacionalidad norteamericana, perpetrado en septiembre de 1976, generó una amplia reacción contra el régimen de Santiago.

La llegada de la administración Carter significó un duro reajuste én las relaciones bilaterales. Por una parte, Washington pasó a ser un obstáculo para las relaciones extemas chilenas, con su política de defensa de los derechos humanos. Por otra, y como resultado del distanciamiento de la Casa Blanca, el régimen militar perdió un apoyo que le había resultado esencial en la etapa de instalación.

Sin embargo, paradójicamente, el distanciamiento político que implicó una disminución significativa de la ayuda pública norteamericana, no se reflejó en el nivel de la transferencia de recursos financieros. En efecto, la reducción de la ayuda (de 183,6 millones de dólares durante el período 1974-1976, a 68,9 millones en el periodo 1977-1980), así como lä reducción de los créditos del Eximbank y otros organismôs no considerados como ayuda, que pasaron de 141,8 millones a 46 millones, si bien reflejaban un cambio en la política de la Casa Blanca respecto de Santiago, fueron ampliamente compensadas con transferencias crediticias privadas, con lo cual la utilización de sanciones económicas como recurso político de presión para mejorar la situación política intema chilena fue debilitada por la permeabilidad que el proceso de transnacionalización financiero ofrecía a los operadores privados y públicos.

Las relaciones bilaterales pasaron nuevamente a un nivel de cordialidad durante la primera parte de la nueva administración norteamericana. Hay una relativa mejoria por la identidad de intereses y la visión del

${ }^{93}$ Esta interpretación se puede profundizar en Stanley Hoffmann, Orden Mundial o Primacia, (Buenos Aires: Grupo Editor Latinoamericano, 1988), Capitulo II. 
mundo -especialmente por el alto perfil ideológico anticomunista y antisoviético que asume la administración Reagan-y que ambos gobiernos comparten.

Tal como señalan Heraldo Muñoz y. Carlos Portales, el gobierno de Ronald Reagan levantó la prohibición impuesta por Carter al otorgamiento de créditos del Eximbank para financiar exportaciones norteamericanas a Chile y también modifícó el voto negativo que Estados Unidos habia mantenido en relación a los créditos para Chile en el Bạco Mundial y en el Banco Interamericano de Desarrollo.

Washington adoptó una política de "diplomacia silenciosa" para presionar al gobierno militar de Santiago, rompiendo así con la política más abierta y pública de oposición de Carter.

Esta política duró hasta que las protestas en Chile contra el gobiemo militar hicieron pensar a la. Casa Blanca en un desenlace "a la nicaragüense" de la situación interna chilena; lo que alentó un cambio. A partir de allí (1983-1986), los Estados Unidos deciden jugar la carta de la oposición democrática y una salida transicional negociada, y la falta de progresos hacia la transición negociada se constituyó en el nuevo motivo de divergencias entre Washington y Santiago. Pero el conflicto queda restringido al ámbito político-diplomático, mientras las relaciones económicas progresan significativamente (comercio, inversiones, préstamos). Sin embargo, las relaciones del ámbito militar fueron excluidas del área política conflictiva, ya que el gobierno norteamericano intensificó la búsqueda de un estrechamiento de los vínculos militares. La recomposición de los vínculos militares con las Fuerzas Armadas fue uno de los objetivos prioritarios de la politica estadounidense durante todo ese periodo. ${ }^{94}$ En esta línea, aumentaron las visitas militares bilaterales: visita del Subsecretario de Defensa, Néstor Sánchez; visitas de los Comandantes en Jefe de la Fuerza Aérea y de la Marina a Washington; visita a Santiago del asesor político del Comando Sur de las Fuerzas Armadas norteamericanas, Richard Moon y del general de la Fuerza Aérea norteamericana, Herman Thompson; la participación chilena en la operación Unitas XXVI y la ampliación del aeropuerto de la Isla de Pascua para su utilización como pista alternativa de emergencia durante los vuelos de los transbordadores de la NASA, constituyeron los más importantes ejemplos de ese alto nivel de relaciones. Esta política de acercamiento militar se ajustaba a la estrategia norteamericana de recons-

${ }^{94}$ H. Muñoz \& C. Portales, op. cit., p. 123. 
truir y mantener un instrumento clave de presión e influencia sobre el gobierno militar.

Sin embargo, la democracia no era por entonces el objetivo más importante de los intereses norteamericanos en Chile, sino uno entre otros de ellos. Pero, a comienzos de 1986, el objetivo de apurar una salida democrática en Chile pasó a ser de mayor importancia. Una de las razones en la que coinciden algunos autores es la que considera el reemplazo de funcionarios conservadores de la administración Reagan por otros más pragmáticos, especialmente en el Departamento de Estado, quienes consideraban la estabilidad democrática como funcional a los intereses norteamericanos.

Sin embargo, el apoyo norteamericano a la economía chilena siguió siendo fundamental para la continuidad del programa y proyecto económico del gobierno militar. El apoyo multilateral, a través de acuerdos para renegociar deuda externa y la concesión de nuevos créditos, fue un claro ejemplo de que Santiago seguía contando con el apoyo norteamericano.

Queda claro que el impulso norteamericano hacia una salida negociada -una transición democrática- lo fue en la búsqueda de una salida sin fracturas violentas o conflictos entre el gobiemo militar y la oposición, para lo cual el carácter político de la dirigencia del recambio debía ser aceptable tanto para el gobiemo militar como para el gobiemo norteamericano.

Se concluye, en este sentido, que la política (político-diplomática) de la administración Reagan hacia el gobierno militar no fue uniforme. A una primera etapa de simpatía, con relaciones estrechas y cordiales, siguió otra de mayores presiones y relaciones más formales y luego una última en la cual Washington buscaba una salida de transición; aunque resguardando sus intereses políticos y sus vínculos con las Fuerzas Armadas. Esto explica por qué esa política tuvo rasgos ambiguos y contradictorios, ya que coincidía una línea de apoyó (siempre existente) con períodos de mayor o menor crítica sobre la situación política interna y la violación de los derechos humanos. Por otra parte, la politica económica fue coherente con los intereses más vitales de Estados UUnidos en Chile, que no pasaban precisamente por impulsar la democracia.

En definitiva, la ayuda económica al gobierno militar chileno en un contexto internacional de restricciones y ajuste fue privilegiada, gracias al fuerte y permanente respaldo del gobiemo norteamericano durante la mayor parte de la administración Reagan. Este apoyo era tanto de lectura 
política, como también un impulso a la continuidad de la política financiera y comercial seguida por el gobierno chileno.

Al mismo tiempo, "la conducción de la política económica del gobierno militar se ajustó a los requerimientos de los organismos financieros multilaterales, de la banca privada y del gobiemo de los Estados Unidos, particularmente en la forma de generar excedentes para el servicio de la Deuda Externa". ${ }^{95}$ Este disciplinamiento fue recompensado con la asignación de créditos y apoyo multilateral, mientras que otros países latinoamericanos no recibían igual trato, aún en el caso de gobiernos que estaban realizando una dura transición democrática.

El desenlace de los acontecimientos -incluyendo como fulminante el plebiscito de octubre de 1988-junto con el fin de la Guerra Fría, le restaron dramatismo y peligrosidad a la transición chilena a los ojos de Washington; pero, como es dable suponer, las huellas de las relaciones bilaterales durante la vigencia del régimen militar y el papel jugado por Estados Unidos, tanto en su etapa de instalación como en su permanencia, perdurarian en las relaciones entre ambos países.

Sin embargo, la política implementada por el primer gobierno democrático de la transición (Aylwin) -y continuada por el siguientebuscó establecer un nuevo marco político a las relaciones bilaterales fundado en el pragmatismo y en la ausencia de visiones globales condicionantes así como de preconceptos, en la cual la dimensión de las relaciones económicas bilaterales y su impacto sobre la economía y el desarrollo chilenos así como una lectura acotada de las tendencias de la economja y la política mundiales tuvieron un pesorsigniificativo. Junto a ello, el aumento continuado de la inversión extranjerazdirecta -tanto la de origen norteamericano como aquella derivada del ejemplo que ésta podía sugerir sobre la definición de los inversores y los gobiernos de las potencias capitalistas-, el impulso a la continuidad de la política económica y comercial de apertura chilenas; la aceptación de Chile como un socio eventual de los Estados Unidos; la negociación de una Acuerdo de Libre Comercio y el ingreso de Chile al NAFTA, para concluir que la posición actual de Estados Unidos en la economía chilena es de lejos (en términos globales) la más influyente y determinante entre los socios comerciales externos de Chile, son.otros de los argumentos que han jugado en favor de esta política,

El pragmatismo político aplicado por el gobierno chileno a sus relaciones con Estados Unidoș se justifica, pues, por el profundo grado de vinculación asimétrica de la economía chilena con la economía

95 Ibid., pp. 142-143. 
norteamericana y, también, porque la cicontinuidad y profundización de las relaciones económicas de Chile cóñesă potencia son fundamentales y funcionales a la expansión de la iñâágen internacional de Chile como un país en desarrollo con una economía estable, en pleno y acelerado crecimiento, lo que favorece -en el seno del capitalismo central-la elección del país como receptor de nueva inversión extranjera directa (IED).

La lectura histórica de la canasta de exportaciones chilleñas a lós Estados Unidos señala que el país ha sido primordialmentè ứ exportador de recursos naturales y sus derivados, exportaciones que han sido beneficiadas por el universo arancelario norteamericano. Pero, al estudiar la estructura del mismo se observa que en la mayoría de los sectores existe un gran escalonamiento arancelario para proteger a la industria interna norteamericana, lo cual puede ser considerado como una de las explicaciones del por qué no se han establecido en Chile industrias procesadoras de sus recursos naturales. En la medida que Chile increménte el valor agregado de sus productos (industrialización), ese eśçalónamiento se constituirá en un obstáculo de cierta importancia.

\section{Evaluación comercial sobre el período 1992/1994.}

Como se observa en el cuadro siguiente, la tendencia hacia un mayor crecimiento de las importaciones desde Estados Unidos respecto de las exportaciones chilenas hacia ese mercado se acentúo, lo que se tradujo a partir de 1992 en una Balanza Comercial desfavorable para Chile. De los 14,4 millones de dólares de la balanza comercial favorables para Chile en 1991, se llega en 1992 a 335,58 millones de dólares desfavorables para ese pais, pasando a 625,85 millones de dólares en 1994.

\section{Balanza comercial Chile - Estados Unidos (en millones de US\$)}

\begin{tabular}{lrrr}
\hline & 1992 & 1993 & \multicolumn{1}{c}{1994} \\
\hline Total Exportaciones & $1.649,30$ & $1.654,84$ & $2.012,09$ \\
Total Importaciones & $1.984,88$ & $2.477,43$ & $2.637,94$ \\
Balanza Total & $-335,58$ & $-822,59$ & $-625,85$ \\
\hline
\end{tabular}

Fuente: Departamento de Comercio Exterior de ODEPA.

El incremento en la relación bilateral del saldo desfavorable para Chile tuvo que ver con la tendencia, que se manifestó principalmente a 
partir del año 1989, del crecimiento a una tasa mayor de las impóitaêtoniès desde ${ }_{i}$ los Estados Unidos con respecto a las exportaciones chilèná̀ì. A fue que en 1992 las exportaciones chilenas hacia los Estados Unidos crecieron un $3,33 \%$, contra un $25,47 \%$ de las importaciones hacia Chile; y en 1993 un $0,33 \%$ contra un $24,81 \%$. Si bien en 1994 se produjo un notable aumento de las exportaciones chilenas hacia los Estados Unidos, registrando un crecimiento con respecto al año anterior cercano a un $21,6 \%$, unido a un menor crecimiento de las importaciones $(6,48 \%)$, la tendencia manifestada en los años anteriores hizo que aún prevaleciera un saldo neto desfavorable para Chile en la balanza comercial de la relación bilateral.

Las exportaciones agrícolas hacia los Estados Unidos representaron el 37\% de las exportaciones totales chilenas hacia ese país en el año 1992, disminuyendo al $31 \%$ en 1994.

Los principales sectores de importación y de exportación en el comercio con.Estados Unidos, en los últimos años; püeden apreciarse en los cuadros siguientes:

\begin{tabular}{|c|c|c|c|c|}
\hline \multicolumn{5}{|c|}{$\begin{array}{l}\text { Principales productos importados desde Estados Unidos } \\
\qquad 1991 / 1994 \text { (en miles de USS CIF) }\end{array}$} \\
\hline Productos & 1991 & 1992 & 1993 & 1994 \\
\hline Semillas/cereales & 38.008 & 32.990 & 54.708 & 42.120 \\
\hline $\begin{array}{l}\text { Prods. químicos (incluidos prods. ter- } \\
\text { minados, plástico y caucho) }\end{array}$ & 300.230 & 377.622 & 744.000 & 1.045 .310 \\
\hline Papel (prensa, varios, cartón, etc.) & 32.802 & 43.546 & 40.534 & 49.980 \\
\hline Textiles (tejidos, hilados, etc.) & 51.527 & 68.945 & 68.270 & 60.182 \\
\hline $\begin{array}{l}\text { Materiales y herramientas p/construc- } \\
\text { ción }\end{array}$ & 46.320 & 42.627 & 72.190 & 70.200 \\
\hline $\begin{array}{l}\text { Maq. e instrumentos eléctricos y a pre- } \\
\text { siön (calderas, bombas, compresoras, } \\
\text { hornos, etc.) }\end{array}$ & $\therefore 74.491$ & 87.523 & 102.233 & 136.400 \\
\hline $\begin{array}{l}\text { Otras máquinas e instrumentos (princi- } \\
\text { palmente excavadoras, cavadoras, etc.) }\end{array}$ & 128.405 & 188.372 & 253,154 & $\ldots 262.446$ \\
\hline $\begin{array}{l}\text { Autos, chasis, repuestos (se. incluye re- } \\
\text { puestos p/embarcaciones y helicópte- } \\
\text { ros) }\end{array}$ & 67.436 & $\begin{array}{ll}\because 36.571 \\
\end{array}$ & $\begin{array}{l}\therefore \\
164.595\end{array}$ & $\begin{array}{rr}0 \\
142,372 \\
\end{array}$ \\
\hline $\begin{array}{l}\text { Total importaciones por año desde Es- } \\
\text { tados Unidos }\end{array}$ & 1.581 .889 & 1.984 .889 & 2.477 .433 & 2.637 .949 \\
\hline
\end{tabular}

Fuente: Banco Central de Chile. Los sectores y productos considerados en este cuadro representan alrededor del 70\% del total de las importaciones procedentes de los Estados Unidos. 


\begin{tabular}{|c|c|c|c|c|}
\hline \multicolumn{5}{|c|}{$\begin{array}{l}\text { Principales productos chilenos exportados a los Estados } \\
\text { Unidos } 1991 / 1994 \text { (en miles de US\$ FOB) }\end{array}$} \\
\hline Productos & 1991 & 1992 & 1993 & 1994 \\
\hline Prods. de mar frescos/congelados & 140.184 & 167.145 & 188.499 & 199.246 \\
\hline $\begin{array}{l}\text { Verdura-fruta refrigerada, preparada, } \\
\text { fresca }\end{array}$ & 497.040 & 437.900 & 425.400 . & 458.700 \\
\hline $\begin{array}{l}\text { Cereales-semillas (maiz siembra, semi- } \\
\text { llas legumbres, semillas melón y san- } \\
\text { dia, etc.) }\end{array}$ & 13.300 & 33.600 & 22.800 & 30.300 \\
\hline $\begin{array}{l}\text { Productos alimenticios (bombones, ca- } \\
\text { ramelos, tomates, jugos de tomate, } \\
\text { puré de tomate, jugos de frutas, etc.) }\end{array}$ & 61.687 & 61.377 & 42.944. & 31.343 \\
\hline Tabaco & 9.800 & 13.000 & 8.500 & 13.400 \\
\hline $\begin{array}{l}\text { Minerales/combustibles (RNP) (sales } \\
\text { varias, de cobre y concentrados, de } \\
\text { molibdeno, fuel oil, gas oil, yodo, etc.) }\end{array}$ & 110.000 & 101.500 & 131.170 & 190.107 \\
\hline $\begin{array}{l}\text { Maderas y productos de madera (listo- } \\
\text { nes, molduras, pastas de coniferas, } \\
\text { arts. vs.) }\end{array}$ & 41.698 & $\begin{array}{r}\vdots \\
53.343 \\
\end{array}$ & 77.411 & 115.021 \\
\hline $\begin{array}{l}\text { Productos textiles (tejidos lana, hila- } \\
\text { dos de rayón, tejidos fibra poliester, } \\
\text { suéteres, jerseys, etc.) }\end{array}$ & 24.483 & 22.797 & 21.632 & 23.846 \\
\hline $\begin{array}{l}\text { Calzados (botin, bota, zapatos de suela } \\
\text { de caucho) }\end{array}$ & 19.313 & 10.383 & 11.184 & 7.398 \\
\hline $\begin{array}{l}\text { Oro/plata (semielaborada, en bruto } \\
\text { aleada, sin alear, en polvo) }\end{array}$ & 157.980 & 182.713 & 166.625 & 233.781 \\
\hline Manufacturas de hierro/ cobre & 333.126 & 373.733 & 317.782 & 424.803 \\
\hline Otros productos industriales & 29.100 & 34.844 & 40.707 & 45.423 \\
\hline $\begin{array}{l}\text { Toial exportaciones por año a Estados } \\
\text { Unidos }\end{array}$ & 1.596 .349 & 1.649 .304 & 1.654 .837 & 2.012 .092 \\
\hline
\end{tabular}

Fuente: Banco Central de Chile. Los sectores y productos considerados en este cuadro representan alrededor del $60 \%$ del universo exportador chileno. En el $40 \%$ restante se encuentran, sin embargo, porcentajes importantes de derivados o procesados de estos mismos productos.

Inversión extranjera directa: posición de Estados Unidos.

La inversión extranjera directa de origen norteamericano se dirigió históricamente al sector extractivo. La gran expansión de esta IED en los últimos diez años no refleja un cambio de perfil de la misma; es decir, la inversión sigue dirigiéndose al sector extractivo, lo que reflejaria una tendencia a seguir manteniendo el mismo tipo de vinculación económica 
que caracterizó históricămente las relaciones comerçiales bilaterales: Estados Unidos como exportador de productos manufacturados y de bienes de capital y Chile como exportador de productos básicos (recursos naturales y productos agrícolas).

La participación de la inversión norteamericana en Chile durante el período 1970-1973, fue marginal por problemas de orden político y como consecuencia de la aplicación en Chile del programa económico socialista, a lo que se agregó el cumplimiento por parte de Chile de las normativas convenidas en la Junta del Acuerdo de Cartagena.

A partir de 1974, la IED de origen norteamericärio retorna a Chile.

Entre 1974 y 1994, Estados Unidos fue el primer inversor extranjero en Chile, concentrando el $37 \%$ de la inversión materializada en el país durante ese período. El monto de las inversiones totales materializadas en ese lapso ascendió a US\$12.527,7 millones.

El $40 \%$ de las inversiones producidas de acuerdo al DL 600 en el período 1983-1989 tuvo procedencia norteamericana, lo cual representó más del 50\% del total de las inversiones autorizadas en Chile para 1989.

Considerando el periodo 1974-1992, la participación de Estados Unidos en el total de inversión autorizada correspondió al $41,7 \%$, con un total de $8.941,2$ millones de dólares, mientras que el total materializado correspondió al $37,1 \%$ del total de la inversión materializada, por un valor de 3.023,7 millones de dólares. El cuadro siguiente refleja la altísima participación de la inversión de origen norteamericano en el total de inversiones extranjeras en Chile.

Inversión autorizada y materializada según país de origen. Período 1974-1992 ${ }^{96}$ (millones de US\$)

\begin{tabular}{lrrrr}
\hline \multirow{2}{*}{ País } & \multicolumn{2}{c}{ Total autorizado } & \multicolumn{2}{c}{ Total materializado } \\
& Valor & Part. & Valor & Part. \\
\hline Estados Unidos & $8.941,2$ & $41,7 \%$ & $3.023,7$ & $37,1 \%$ \\
Canadá & $3.369,4$ & $15,7 \%$ & 664,1 & $8,2 \%$ \\
Reino Unido & $1.665,3$ & $7,8 \%$ & 741,0 & $9,1 \%$ \\
Australia & $1.017,4$ & $4,7 \%$ & 520,6 & $6,4 \%$ \\
Finlandia & $1.000,8$ & $4,7 \%$ & 34,8 & $0,4 \%$ \\
Japón & 872,7 & $4,1 \%$ & 356,2 & $4,4 \%$ \\
España & 721,1 & $3,4 \%$ & 610,8 & $7,5 \%$ \\
Islas Caimán & 538,0 & $2,5 \%$ & 129,1 & $1,6 \%$
\end{tabular}

${ }^{96}$ Ministerio de Relaciones Exteriores de Chile, Revista Chile, Santiago, Nº45, Julio 1993, p. 28. 
R. Bernal-Meza / Evolución histórica de las ...

\begin{tabular}{|c|c|c|c|c|c|c|}
\hline Nueva Zelandia & 400,0 & $1,9 \%$ & 360,6 & & & $4,4 \%$ \\
\hline Sudáfrica & 382,4 & $1,8 \%$ & 140,9 & & & $1,7 \%$ \\
\hline Holanda & 270,0 & $1,3 \%$ & 214,0 & & & $2,6 \%$ \\
\hline Panamá & 260,4 & $1,2 \%$ & 168,8 & & & $2,1 \%$ \\
\hline Org.Internacionales & 239,1 & $1,1 \%$ & 119,5 & & $\because$ & $1,5 \%$ \\
\hline Francia & 206,2 & $1,0 \%$ & 157,9 & & : & $1,9 \%$ \\
\hline Islas Bahamas & 192,5 & $0,9 \%$ & 39,9 & & & $0,5 \%$ \\
\hline Luxcmburgo & 167,4 & $\cdot 0,8 \%$ & 100,5 & $\because, j:$ & & $1 ; 2 \% \ldots \ldots$ \\
\hline Bermudas & 136,1 & $0,6 \%$ & 42,4 & & & $0,5 \%$ \\
\hline Alemania & 125,7 & $0,6 \%$ & 88,1 & & & $1,1 \%$ \\
\hline Brasil & 117,1 & $0,5 \%$ & 98,7 & & & $1,2 \%$ \\
\hline Suiza & 117,0 & $0,5 \%$ & 104,6 & & & $1,3 \%$ \\
\hline Argentina & 112,0 & $0,5 \%$ & 54,6 & & & $0,7 \%$ \\
\hline Liechtenstein & 108,4 & $0,5 \%$ & 44,1 & & $\because$ & $0,5 \%$ \\
\hline Italia & 54,5 & $0,3 \%$ & 38,0 & & & $0,5 \%$ \\
\hline Uruguay & 52,0 & $0,2 \%$ & 38,9 & & $\cdots \ldots$ & $0,5 \%$ \\
\hline Singapur & 50,0 & $0,2 \%$ & 3,0 & & $\therefore$ & $0,0 \% \ldots$ \\
\hline Suecia & 47,6 & $0,2 \%$ & 38,5 & & & $0, \ddot{5 \%}$ \\
\hline Hong Kong & 44,5 & $0,2 \%$ & 37,8 & & & $0,5 \%$ \\
\hline Nueva Guinea & 40,0 & $0,2 \%$ & 40,0 & & : & $0,5 \%$ \\
\hline Antillas Holandesas & 37,8 & $0,2 \%$ & 21,1 & & & $0,3 \%$ \\
\hline China & 20,0 & $0,1 \%$ & 19,2 & & $\because$ & $0,2 \% \approx 0$ \\
\hline Bélgica & 19,0 & $0,1 \%$ & 14,2 & & & $0,2 \%: 3$ \\
\hline Colombia & 15,2 & $0,1 \%$ & 14,1 & & & $0,2 \%$ \\
\hline México & 14,9 & $0,1 \%$ & 13,3 & & & $0,2 \%$ \\
\hline Corea & 14,3 & $0,1 \%$ & 3,8 & & & $0,0 \%$ \\
\hline Perú & 13,4 & $0,1 \%$ & 5,1 & & , & $0,1 \%$ \\
\hline Austria & 11,6 & $0,1 \%$ & 7,5 & & & $0,1 \%$ \\
\hline Dinamarca & 11,0 & $0,1 \%$ & 7,9 & & & $0,1 \%$ \\
\hline Yenezuela & 9,4 & $0,0 \%$ & 6,0 & & & $0,1 \%$ \\
\hline Costa Rica & 7,2 & $0,0 \%$ & 2,7 & & & $0,0 \%$ \\
\hline Nonuega & 6,8 & $0,0 \%$ & 2,9 & & $\therefore$ & $0,0 \%$ \\
\hline Chipre & 6,0 & $0,0 \%$ & 6,0 & & & $0,1 \%$ \\
\hline Taiwán & 5,3 & $0,0 \%$ & 0,6 & & . & $0,0 \%$ \\
\hline Israel & 3.6 & $0,0 \%$ & 1,3 & & & $0,0 \% \cdot \therefore \therefore$ \\
\hline Barbados & 3,5 & $0,0 \%$ & 3,5 & & & $0,0 \%$ \\
\hline Ecuador & 3,3 & $0,0 \%$ & 0,9 & & & $0,0 \%$ \\
\hline Rumania & 3,1 & $0,0 \%$ & 3,1 & & ' & $0,0 \%$ \\
\hline Bolivia & 2,3 & $0,0 \%$ & 0,3 & $\therefore$ & & $0,0 \%$ \\
\hline Honduras & $2, \dot{0}$ & $0,0 \%$ & 0,1 & & & $0,0 \%$ \\
\hline Islandia & 2,0 & $0,0 \%$ & 1,8 & & & $\therefore 0 ; 0 \%$ \\
\hline Paraguay & 1,6 & $0,0 \%$ & 0,7 & & & $0,0 \%$ \\
\hline Libcria & 1,1 & $0,0 \%$ & 0,4 & & & $0,0 \%$ \\
\hline Jordania & 0,6 & $0,0 \%$ & 0,2 & & $\therefore$ & $0,0 \%$ \\
\hline El Salvador & 0,4 & $0,0 \%$ & 0,3 & & & $0,0 \%$ \\
\hline Egipto & 0,4 & $0,0 \%$ & 0,3 & & & $0,0 \%$ \\
\hline Emiratos Arabes & 0,2 & $0,0 \%$ & 0,1 & & & $0,0 \%$ \\
\hline Vanuatu & 0,2 & $\cdot 0,0 \%$ & 0,0 & & & $0,0 \%$ \\
\hline India & 0,2 & $0,0 \%$ & 0,2 & & & $0,0 \%$ \\
\hline Guaternala & 0,0 & $0,0 \%$ & 0,0 & & & $0,0 \%$ \\
\hline TOTAL & $21.465,0$ & $100,0 \%$ & $8.148,3$ & & & $100,0 \%$ \\
\hline
\end{tabular}

Fuente: Comité Inversiones Extranjeras. Los valores corresponden a clasificación según origen de la casa matriz; cifras provisorias al 31 de diciembre de 1992. Los montos acumulados incluyen transferencias entre países (cesiones de derechos) registradas a la fecha del informe. 
Según sector de destìno, la inversión autorizada y materializada de acuerdo al DL 600 señala que el sector minero concentraba en el período 1974-1992 el 69,2\% dèl total de la inversión autorizada, con un valor de $14.844,8$ millones de dólares y un $53 ; 2 \%$ de la inversión total materializada, por un valor de 4.336,7 millones de dólares.

\section{Nuevos rumbos en las relaciones económicas.}

A partir de junio de 1995, Chile inició la negociación con los miembros del NAFTA sobre un futuro Acuerdo de Libre Comercio. La adecuación de su estructura productiva acarreará a Chile costos y beneficios. Entre los primeros, la adecuación a los estándares medioambientales y técni$\mathrm{cos}_{\text {; }}$ así como de su institucionalidad jurídico-legal. De los segundos, la adptación a reglas de juego cuyos efectos permitirán a la economía chilena enfrentar exigencias que mejorarán su competitividad internacional.

\section{Conclusiones.}

La influencia económica, política, militar y financiera de Estados Unidos en Chile es la más relevante que cualquier otra potencia haya tenido en su historia como nación políticamente independiente. El fundamento de este proceso ha sido el desarrollo del comercio y las inversiones, iniciado al comenzar el presente siglo, y cuyo resultado se ha traducido en dependencia. Esta posición relevante de los Estados Unidos fue independiente de su condición de potencia hegemónica mundial, pero se fue acrecentando en la medida que la asimetría entre ambos paises se consolidaba como una dinámica irreversible.

Sin embargo, la historia de las relaciones, dificultades y conflictos bilaterales no se inicia en el presente siglo. Como hemos visto, el siglo $\mathrm{XlX}$ marca todo un periodo de competencia, rivalidad y desconfianza, cuyo clivage se produce hacia el final del gobiemo de Balmaceda y la Revolución de 1891, donde quedan de manifiesto las razones profundas del inicio de una relación de asimetria, caracterizada por el diferente nivel de desarrollo y poder entre uno y otro actor.

Al evaluar más de 180 años de historia en las relaciones bilaterales, en ellas han sobresalido las tensiones y las disputas por söbrie Tos acuerdos y la cooperación, en un proceso que comenzó con la rivalidad y la competencia, para terminar en una profunda dependencia, sobre la cual 
existe hoy una relación asimétrica que ubica a Chile en el racimo de países hacia los cuales se expande la nueva regionalización con base en Estados Unidos.

$\therefore$ Paradójicamente, el antinorteamericanismo ha sido una posición común tanto para la izquierda como para la derecha política chilenas durante un largo período, posición que fue evolucionando hacia posiciones más pragmáticas durante el régimen militar de Pinochet. La izquierda encontró en distintos actores y estructuras de poder norteamericanos un aliado en su lucha contra la dictađura, coincidiendo en la política de derechos humanos, mientras que la derecha encontró nuevamente en Estados Unidos un socio privilegiado para hacer negocios.

Hacia finales de la década de los años 80 , a partir de la formulación de la "Iniciativa para las Américas" y la propuesta de un acuerdo de libre comercio de América del Norte, Estados Unidos pasó a constituirse en un actor fundamental en la formulación de la política exterior chilena. El volumen de la inversión extranjera directa de origen norteamericano y el peso del comercio en el intercambio bilateral, presentan a Estados Unidos como un actor clave de la expansión económica chilena futura.

En la actual etapa de globalización y regionalización de la economía mundial, ${ }^{97}$ las relaciones con Estados Unidos aparecen para Chile como un tema central. Por una parte, porque contribuyen a afianzar la imagen internacional del país; por otra, porque la negociación de un acuerdo de libre comercio con esa potencia puede permitir a Chile su incorporación al bloque regional del NAFTA. Tal como hemos señalado, los paises miembros del NAFTA representaron, a diciembre de 1994, e1 50\% del total de proyectos de inversión materializados, con un total de $6.387,8$ millones de dólares, mientras que en el ranking de inversiones comprometidas a futuro, Estados Unidos encabeza la lista con e1 48\%. Del total autorizado por el Comité de Inversiones Extranjeras de Chile (29.543 millones de dólares), Estados Unidos concentra alrededor de 14.100 millones de dólares); siguiéndole Canadá, con 4.489,5 millones de dólares.

De seguir estas perspectivas, se acentuaría la vinculación entre Chile y Estados Unidos; evidentemente también la dependencia, en la medida que las relaciones comerciales se asientan todavía en el clásico clivage "centro-periferia". Santiago afianzaría su posición como un actor regio-

\footnotetext{
${ }^{97}$ Ver el desarrollo e impacto de estos procesos sobre las economias en desarrollo en Raúl Bernal-Meza, América Latina en La Economia Politica Asundial, (Buenos Aires: Grupo Editor Latinoamericano, 1994), Primera Parte.
} 
nal relevante para los Estados Unidos (dado el volumen de su inversión extranjera realizada y comprometida a futuro).

Se concluye también que los problemas centrales de la agenda bilateral están hoy concentrados en el área comercial. El desarrollo de las relaciones económicas, comerciales y financieras de Chile con Estados Unidos merecen un tratamiento más amplio, en el cual poner a consideración los aspectos positivos y negativos de tal proceso de vinculación, así como poner de relevancia las dificultades y problemas que existen en este campo, en-la actual agenda bilateral. Como se podrá apreciar allí, las mayores dificultades para Chile están en relación con el impacto interno de un acuerdo de libre comercio; en la negociación del NAFTA, especialmente en lo que respecta a las politicas de dumping y anti-dumping y en el tema del resarcimiento que pide Chile por los daños en el caso de las uvas envenenadas. Mientras que en los temas de la agenda económica y comercial intemacional, el acortamiento de los plazos propiciado por Estados Unidos para que los países en desarrollo implementen los acuerdos de la Ronda Uruguay del GATT (en especial los referidos a las patentes), es el más relevante.

En conclusión, Chile está hoy mucho más ligado a Estados Unidos de lo que históricamente lo fue con cualquier metrópoli y esa tendencia apunta a profundizarse en el futuro. 